OPEN ACCESS

Edited by:

Tao Wu,

Institute of Organic Chemistry and Biochemistry (ASCR), Czechia

Reviewed by:

Chuan-Feng Chen, Institute of Chemistry (CAS), China

Chuanliang Feng,

Shanghai Jiao Tong University, China

*Correspondence:

Tingchao He

tche@szu.edu.cn

Specialty section:

This article was submitted to Physical Chemistry and Chemical

Physics,

a section of the journal

Frontiers in Chemistry

Received: 09 March 2020

Accepted: 01 May 2020

Published: 12 June 2020

Citation:

Gao Y, Ren C, Lin X and He T (2020)

The Progress and Perspective of Organic Molecules With Switchable Circularly Polarized Luminescence.

Front. Chem. 8:458.

do: $10.3389 /$ fchem.2020.00458

\section{The Progress and Perspective of Organic Molecules With Switchable Circularly Polarized Luminescence}

\author{
Yang Gao, Can Ren, Xiaodong Lin and Tingchao He* \\ College of Physics and Optoelectronic Engineering, Shenzhen University, Shenzhen, China
}

Circularly polarized luminescence $(\mathrm{CPL})$ has been under intense research for future applications in high-resolution 3D displays, smart sensors, and information technologies. Different types of CPL materials have been developed, but neither the handedness nor the asymmetrical luminescence degree can be inferred from the material composition or the components. CPL materials with switchable handedness or emission wavelength play an important role, reducing the need for repetitive bottom-up synthesis. Here, we have presented switchable CPL behaviors toward multiple reported stimuli, including light irradiation, host-guest interaction, metal ions, $\mathrm{pH}$, solvent, temperature, etc. This summary and discussion of the effective stimuli is aimed to promote rational future material exploration and boost related multidisciplinary applications.

\footnotetext{
Keywords: circularly polarized luminescence, asymmetrical emission factor, organic material, multiple stimuli, reversible switch
}

\section{INTRODUCTION}

Circularly polarized luminescence (CPL) has been the subject of intense research due to its possible applications in new photonic/photoelectronic devices (Han J. et al., 2018; Zhang et al., 2020), smart sensors, high-resolution 3D displays, information technologies, etc. A variety of CPL materials have been developed to date, including rare-earth metal-based coordination complexes and organic and inorganic molecules/assemblies. Organic luminescent materials have enjoyed a major role in their development due to the wide range of possible structural components, moderate to high emission efficiency, and multiple intra-/inter-molecular interaction modes.

Although there are a number of known strategies to design CPL active materials and a large library of material structures are available (Pop et al., 2019; Sang et al., 2019; Zhao W. L. et al., 2019; Ouyang and Liu, 2020), it is as yet unrealistic to predict related CPL activities for any given structure. Neither the handedness nor the degree of asymmetry can be confidently or accurately predicted from the material composition or the components (e.g., enantiomer excess value). Thus, CPL materials with switchable emission characteristics have been the subject of intense research with the aim of obtaining strong CPL with selective handedness/emission wavelength. Recently, a number of novel approaches have been reported including facile applicable triggers, multiple emissive states, and high-quality emitters. For example, a helical structure incorporating pyrene units showed strong CPL in solution ( $\mathrm{g}_{\text {lum }} \sim 10^{-2}$ ) with handedness, which was invertible by changing the solvent from toluene to DMSO (Takaishi et al., 2020). Also, a switch from circularly polarized fluorescence to ultra-long phosphorescence was achieved for a chiral carbazole phosphor (Li et al., 2020). 


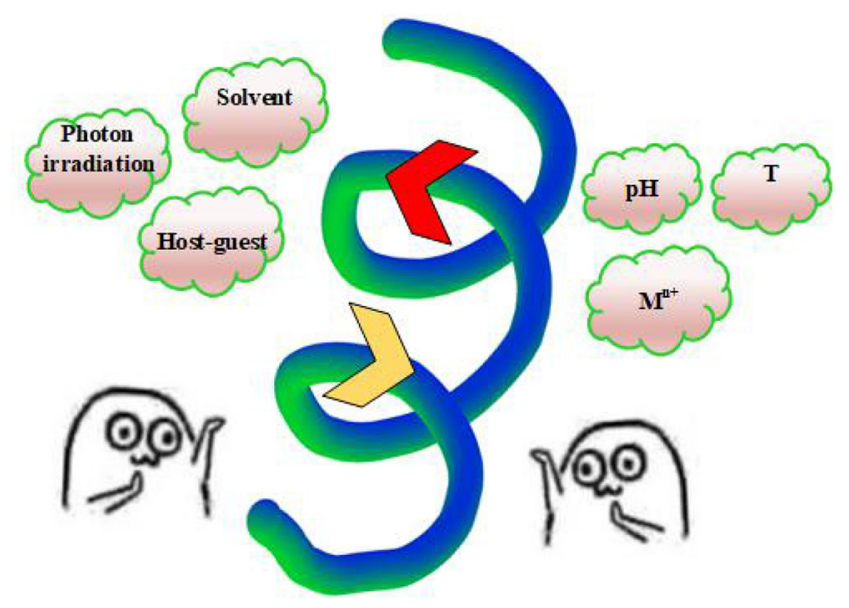

GRAPHICAL ABSTRACT | CPL materials with switchable handedness or emission wavelength toward multiple stimuli, including light irradiation, host-guest interaction, metal ions, $\mathrm{pH}$, solvent, temperature, etc.

Though there have been some recent partial reviews (Ma J. L. et al., 2019; Sang et al., 2019), CPL emitters whose emission is switchable under various stimuli have not been comprehensively reviewed. To fill this gap, a review of switchable CPL behavior is presented herein, including the use of irradiation with light, host-guest interaction, metal ions, $\mathrm{pH}$, temperature, and solvents as stimuli. The discussion will be focused on reversible behavior. Also, a brief explanation of how CPL measurements are performed is included. Hopefully, this review will help promote the design and exploration of future materials and boost development of related multidisciplinary applications.

\section{MEASUREMENT}

To describe CPL materials properly, a number of parameters related to both emission and polarization are involved. Concerning emission behaviors, features usually mentioned include the type of emission (fluorescence, phosphorescence), the emission wavelength $\left(\lambda_{\mathrm{em}}\right)$, quantum efficiency $(\Phi)$, and the emission lifetime $(\tau)$. To characterize spectroscopic features of chiral materials, circular dichroism (CD) and CPL spectra are often used to study the chirality in the ground and excited states, respectively. In the $\mathrm{CD}$ measurement, alternative left- and righthanded light beams pass through the chiral medium, which show different light propagation speeds. Different molar CD $(\Delta \varepsilon)$ can be recorded, and the asymmetric factor of $\mathrm{CD}$ can be calculated according to

$$
g_{a b s}=\frac{\Delta \varepsilon}{\varepsilon}=2 \times \frac{\varepsilon_{L}-\varepsilon_{R}}{\varepsilon_{L}+\varepsilon_{R}}
$$

where $\varepsilon_{\mathrm{L}}$ and $\varepsilon_{\mathrm{R}}$ represents the extinction coefficients for left- and right-handed circularly polarized light, respectively.

The CPL measurement utilizes fluorescence spectrometry with additional compartments for the polarization detection. Usually the excitation beam is polarized with a polarizer before entering the sample, and a modulated circular polarizer is applied after the emission beam to obtain the separate intensity of the lefthanded and right-handed CPL. The level of circular polarization in emission is termed as the dissymmetry or emission g-factor, which is formulated as followed:

$$
g_{\text {lum }}=\frac{\Delta I}{I}=2 \times \frac{I_{L}-I_{R}}{I_{L}+I_{R}}
$$

The theoretical range of $\mathrm{g}_{\text {lum }}$ is from -2 to +2 . For organic molecules in solution, the glum value appears usually in the range of $10^{-5} \sim 10^{-3}$. While in aggregated state or in condensed state, the value increases to $10^{-3} \sim 10^{-1}$.

A switch of the CPL behaviors will be discussed in the context of the aforementioned parameters toward various stimuli.

\section{IRRADIATION WITH LIGHT}

Irradiation with light can influence the CPL behaviors through photo cyclization/de-cyclization, photo induced isomerization, and selected population of specific excited state. Moreover, photoreactions are usually induced by UV radiation and reversed by lower-energy visible light or heat treatment. An on-off switch based on photo cyclization was observed for a photochromic tetrathiazole attached pyrene dye (Hashimoto et al., 2016). When the individual pyrene units were attached via a chiral phenylamine spacer to a tetrathiazole core, the $\pi-\pi$ stacking of two phenylthiazoles resulted in a helical conformation of the core, and two pyrene units were arranged in close proximity. Thus, an intramolecular pyrene excimer was formed (Figure 1), and a CPL signal at $500 \mathrm{~nm}$ with a large $\left|g_{\text {lum }}\right|(0.01)$ was observed. When the helical conformation of the photochromic core was destroyed by UV-light driven cyclization, the pyrene units were separated from each other, and the CPL was quenched. A reversible off-on CPL switch was observed for enantiomeric glutamate gelators modified with a spiropyran moiety (Figure 2) upon alternated UV and visible irradiation 


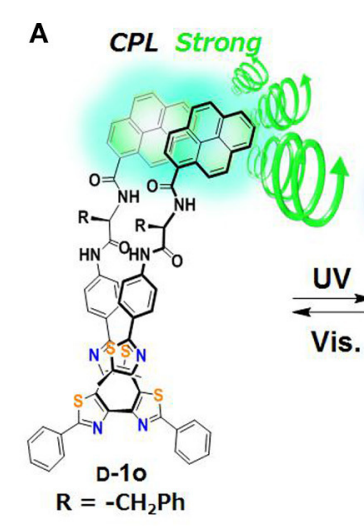

C

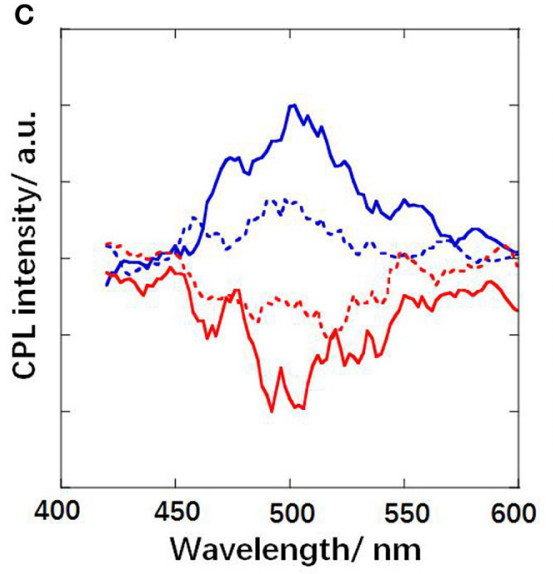

CPL OFF

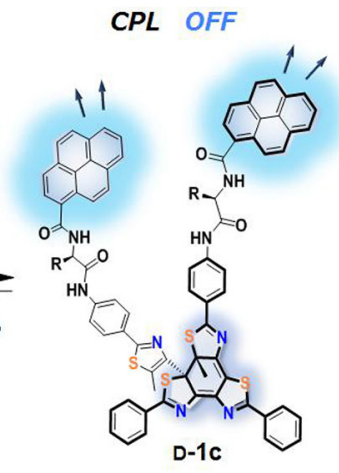

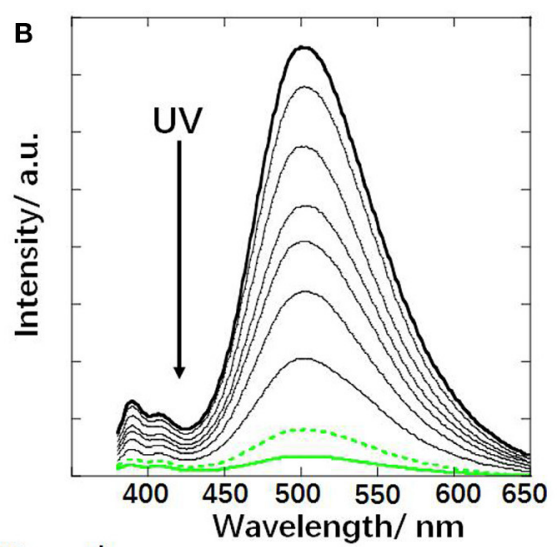

D

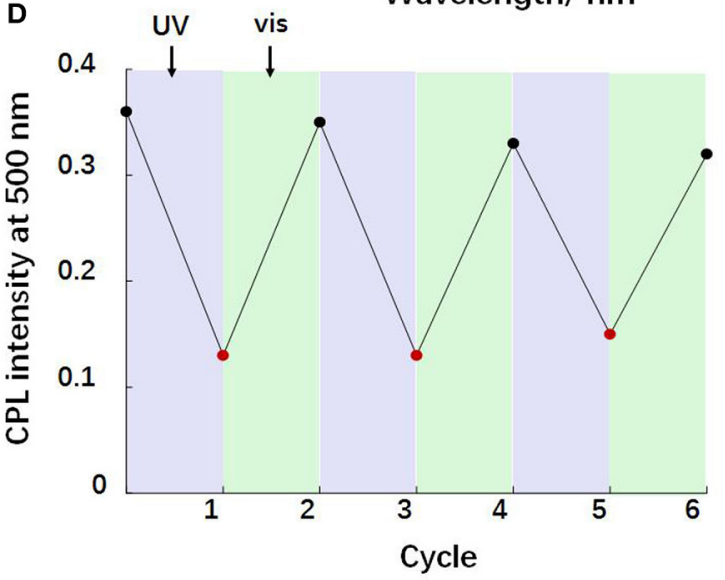

FIGURE 1 | (A) Chemical and CPL change of pyrene stack with tetrathiazole D-1 toward light irradiation. (B) Fluorescence spectral change of L-10 upon UV irradiation $\left(4.6 \times 10^{-6} \mathrm{M}, \mathrm{CHCl}_{3}\right)$. Solid thick black line: 10-form, solid green line: 1c-form, dashed green line: at photo stationary state (PSS), other traces were recorded at an irradiation interval of $5 \mathrm{~s}$. (C) CPL spectra of $10\left(1.7 \times 10^{-4} \mathrm{M}, \mathrm{CHCl}_{3}\right)$. D-form: upper solid blue line; L-form: lower solid red line; dashed lines: at PSS. (D) Reversible CPL intensity changes of D-10 (500 nm, $\mathrm{CHCl}_{3}$ ) (Reproduced with permission; Hashimoto et al., 2016). Copyright 2016, Royal Society of Chemistry.

(Miao et al., 2017). Chirality transfer from the chiral glutamate part to the luminophore was facilitated in the gel state. Upon UV irradiation $(365 \mathrm{~nm})$, the spiropyran unit changed from a colorless closed ring form to a blue zwitterionic merocyanine state accompanied by a red CPL signal (662 nm). After exposure to visible light, the CPL phenomenon was suppressed. This reversible process worked for over 30 cycles when applied in a re-writable printing application.

Light irradiation induced $Z-E$ isomerization of a cyanostilbene-based chromophore resulted in different assembled structures and different related CPL behaviors. Upon exposure to UV-light, cyanostilbene-conjugated glutamide (Figure 3) assembled into different morphologies with inversed CPL sign (Jin X. et al., 2018). The rigid planar (Z)-PCNP formed nanobelts with a lamellar structure, exhibiting left-handed CPL (glum $\sim 4.5 \times 10^{-3}$ ). Upon irradiation at $365 \mathrm{~nm}$, co-existing rigid $\mathrm{Z}$ - and flexible E- isomers assembled to form nanotoroids, which showed right-handed CPL ( $g_{\text {lum }} \sim 6.6 \times 10^{-3}$ ). Similarly, a hostguest supra-gelator, which was formed by encapsulating a chiral $\mathrm{Z}$-cyanostilbene gelator (CG) inside the cavity of $\gamma$-cyclodextrin (CD) (Figure 4), showed reversible off-on CPL, which could be switched using UV-irradiation and heating (Ji et al., 2019). The super-gelator assembled into a bilayer structure and showed CPL signal at $450 \mathrm{~nm}$ with slightly enhanced glum value $(\sim 7.9$ $\times 10^{-3}$ ). The handedness of the super-gel followed the chirality of the CG unit. When the super-gelator was subjected to UV irradiation, isomerization of Z-CG to E-CG took place, the gel collapsed to a suspension of nanospheres, and the CPL signal gradually disappeared. After heating the suspension to form a solution and natural cooling down, the supra-gel was reproduced with the same CPL activity. Moreover, the reversible process was pretty robust, as confinement of the CG unit inside the cavity of $\gamma$-CD make it resistant to fatigue.

Besides the above photo chemical mechanism, the CPL switch was also observed for the photophysical mechanism. Light irradiation at selected wavelength can populate specific excited states, select the emissive state energy, then manipulate the emission probability and the emission lifetime. When a chiral ester chain was linked to the $\mathrm{N}$-position of a carbazole phosphor (Li et al., 2020), an H-type aggregate in the condensed state showed CPL at 369 and $379 \mathrm{~nm}$ ( $\mathrm{g}_{\text {lum }} \sim 0.0031$ ) upon photoexcitation at $365 \mathrm{~nm}$. Moreover, chiral phosphorescence 


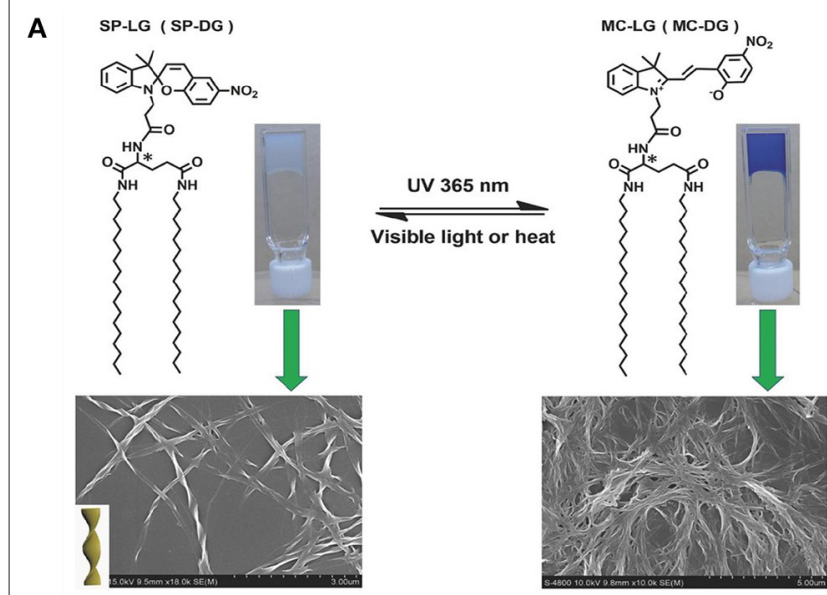

B

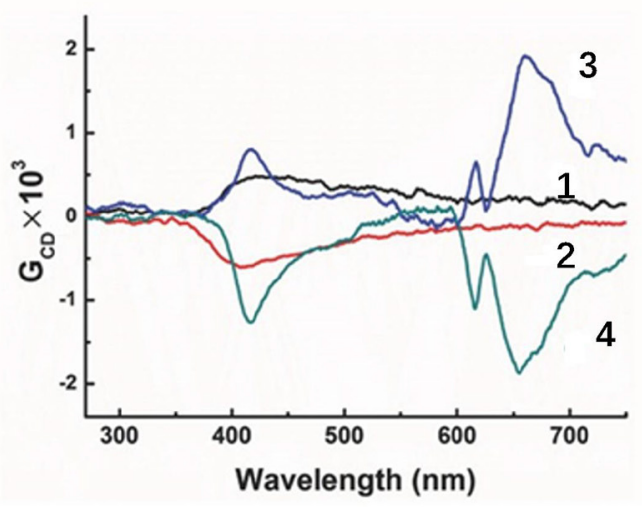

FIGURE 2 | (A) Reversible molecular structure change of spiropyran-modified glutamate gelator between a colorless closed ring state and a blue zwitterionic emissive state toward alternating UV and visible light irradiation, with the related SEM images of SP-LG xerogels (lower part). (B) CPL spectra before UV irradiation (SP-LG (1), SP-DG (2) gels) and after UV irradiation for $8 \mathrm{~min}$ (MC-LG (3), MC-DG (4) gels). Reproduced with permission (Miao et al., 2017). Copyright 2017, John Wiley and Sons.

at 550 and $596 \mathrm{~nm}$ (glum $\sim 0.0027$ ) was observed at room temperature (CP-RTP) after removal of the photo excitation (Figure 5). With extended irradiation time $(365 \mathrm{~nm},<40 \mathrm{~s}$ ), ultralong lifetime CP-RTP (CP-OURTP) was observed by naked eye at room temperature or at low temperature. With elevated temperature at $50^{\circ} \mathrm{C}$, the signal of CP-OURTP diminished within $5 \mathrm{~min}$. After lowering the temperature and repeating photo-activation, the CP-OURTP signal recovered without photo bleaching. Thus, a reversible irradiation turn-on and thermal turn-off CP-OURTP system was developed.

\section{HOST-GUEST INTERACTION}

Engineered rotaxanes with different sizes were demonstrated as containers to encapsulate various guests. Associationdisassociation of the host-guest interaction can serve as a switch for further excimer formation, chirality transfer, chirality inversion, and modulate the on-off state of CPL behaviors. When two polycyclic aromatic chromophores (PAH) (NDI, Pyrene, perylene, and fluorene) were linked to the same face of modified crown-ethers, the close geometrical contact between the $\mathrm{PAH}$ units resulted in the formation of intramolecular excimers (Homberg et al., 2018). G $G_{\text {lum }}$ values as high as $\sim 10^{-2}$ were observed. After selective binding the crown-ether with metal ions such as $\mathrm{Na}^{+}$and $\mathrm{Ca}^{2+}$, the central cryptand acquired a new geometry in which the chromophores were situated far away from each other. The excimers were thus disrupted and the related CPL suppressed.

When the host was changed to chiral (P-/M-) 2,6helic[6]arene cycle, the complexation with guest $4-\left[\left(4^{\prime}-\mathrm{N}\right.\right.$, $\mathrm{N}$-diphenylamino)styryl]-N-methylpyridinium iodide in water showed mirror-imaged CD and CPL signals (Guo et al., 2019). The chirality transfer from the host to the guest resulted in chiral emission of the guest, which was absent for the guest alone. Moreover, the chirality transfer was tunable by temperature and $\mathrm{pH}$. In detail, higher temperature (up to $70^{\circ} \mathrm{C}$ ) caused faster rotation and motion of both the host and the guest, then deteriorated the chirality transfer. Similarly, either lower or higher $\mathrm{pH}$ other than the neutral condition caused lower CPL signals due to either destructed assembly or weakened host-guest interaction. By selecting different inclusion units for a [2]rotaxane, David et. al reported a molecular machine based on-off CPL switch (David et al., 2019). A crown-ether macrocycle with an emitting 2,2'-bipyrene unit was threaded with a secondary ammonium unit, which was linked with chiral D- or L- phenylalanine moieties (Figure 6). When Hbonding was formed between the luminophore and the chiral center under acidic conditions, CPL signals appeared and the handedness was determined by the phenylalanine unit. By contrast under basic conditions, the location of the macrocycle shifted along the thread to the triazolium group, which disabled the aforementioned chirality transfer. Such an on-off switch worked in-situ and only had impact on the CPL signal without quenching the photoluminescence.

In a similar concept, alternative addition of potassium ions $\left(\mathrm{K}^{+}\right)$and cryptand were applied to invert the chirality of a G-quadruplex DNA (G4 DNA) (Chen et al., 2019). Parallel arrangement G4 DNA can be changed to antiparallel arrangement by addition of $\mathrm{K}^{+}$, and the inclusion of luminescent ThT (3,6-dimethyl-2-(4-dimethylaminophenyl)benzo-thiazolium) cations produced different handedness $\left(490 \mathrm{~nm}\right.$, glum $\sim 0.5 \times 10^{-3}$ to $\left.1.5 \times 10^{-3}, 10^{\circ} \mathrm{C}\right)$. Moreover, the ordered assembly of G4 DNA and ThT was promoted at low temperature $\left(10^{\circ} \mathrm{C}\right)$, which could switch $\mathrm{CPL}$ on. Higher temperature $\left(10-70^{\circ} \mathrm{C}\right)$ dissolved the assembly and turned the CPL off. Thus, switching of both handedness and intensity was realized for the assembled complex of G4 DNA and ThT.

\section{METAL IONS}

Metal-ligand interaction has been demonstrated as a facile method to tune CPL performance, by modifying the active chromophores through changes in their conformation, chemical 
A

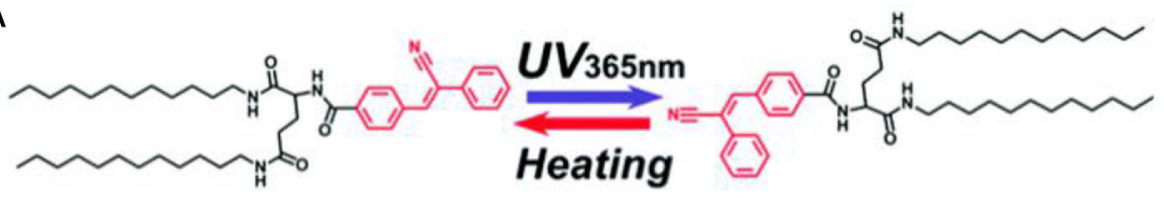

(Z)-PCNP

(E)-PCNP

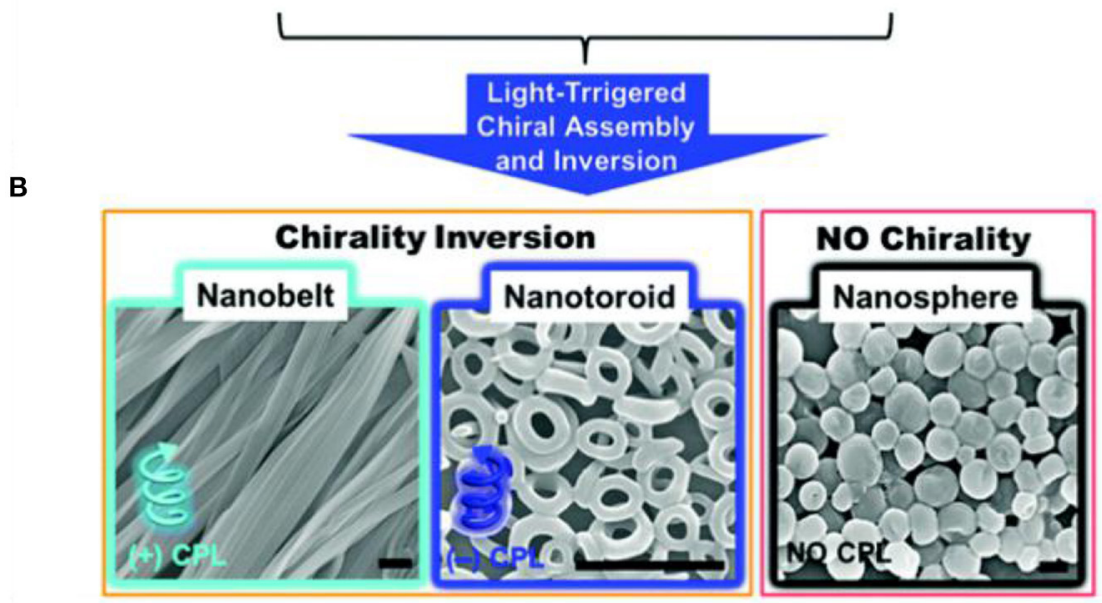

C

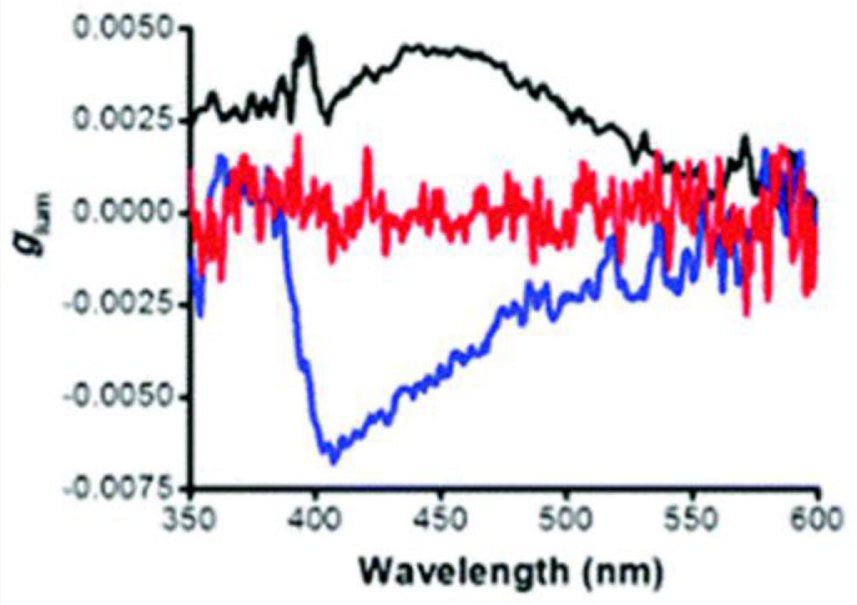

FIGURE 3 | (A) Z-E isomerization of PCNP under UV irradiation. (B) SEM images of the different assembled nanostructures with different irradiation duration (365 nm). From left to the right: Nanobelts (0 min); nanotoroids (15-120 min); and nanospheres (150 min). Scale bar: $1 \mathrm{~mm}$. (C) Glum curves of nanobelts (black), nanotoroids (blue), and nanospheres (red). Reproduced with permission (Jin X. et al., 2018). Copyright 2018, Royal Society of Chemistry.

composition, electronic structure, assembly behavior, etc. This is often reversible by extracting the metal ion with strong chelating ligands. Multiple metal ions have been applied, including $\mathrm{Zn}^{2+}$, $\mathrm{Ag}^{+}, \mathrm{Ni}^{2+}$, and $\mathrm{Al}^{3+}$.

Turn-on of CPL upon coordination of $\mathrm{Zn}^{2+}$ with terpyridine, salen, and dipyrromethene units is accompanied by geometrical changes. A terpyridine suspended bis- aza[6]helicenic unit changed from trans, trans-N,N orientation to cis, and cis-N,N orientation upon coordination with $\mathrm{Zn}^{2+}$ ions (Figure 7A), which resulted in the flip-over of one helicene moiety and charge-transfer from the helicene to the terpyridine part (Isla et al., 2016). Correspondingly, the positive CD signal at $341 \mathrm{~nm}$ decreased slightly and the emission shifted from 420 to $480 \mathrm{~nm}$ with greatly enhanced intensity ( $\Phi_{\mathrm{FL}}$ from 0.08 to 0.19 ), while

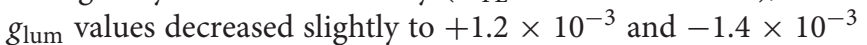
for $(\mathrm{P}, \mathrm{P})$ and $(\mathrm{M}, \mathrm{M})$-isomers, respectively. Moreover, the $\mathrm{Zn}^{2+}$. terpyridine coordination was reversible by adding a competitive ligand $\mathrm{N}, \mathrm{N}, \mathrm{N}^{\prime}$, and $\mathrm{N}^{\prime}$-tetrakis(2-pyridylmethyl)ethane-1,2diamine so that the CPL behavior could be recovered. BINOL based polymer enantiomers with Salen units showed turn-on CPL $\left(465 \mathrm{~nm}\right.$, glum $\sim 8 \times 10^{-3}$ ) upon coordination with $\mathrm{Zn}^{2+}$ (0.3-4.0 equiv) (Meng et al., 2018), with the handedness being determined by the chiral BINOL unit. The CPL signal was induced by effective chirality transfer from the binaphthyl moiety 
A

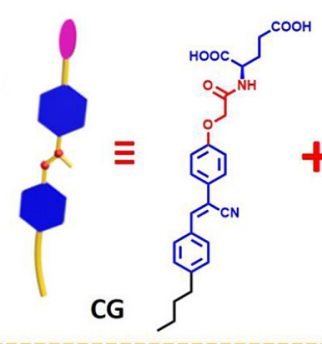

B
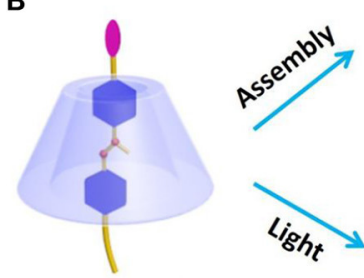

Supra-gelator

$(Z)-C G \subset \operatorname{CyD}(\alpha, \beta, \gamma-)$

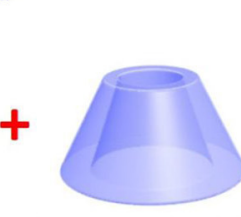

Cyclodextrin (CyD)

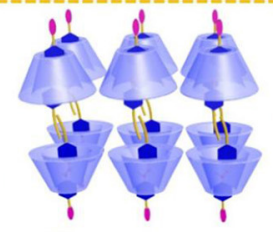

Bilayer Structure

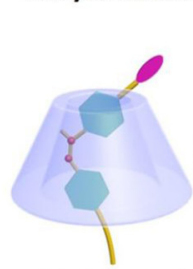

(E)-CG $\subset$ Y-CyD
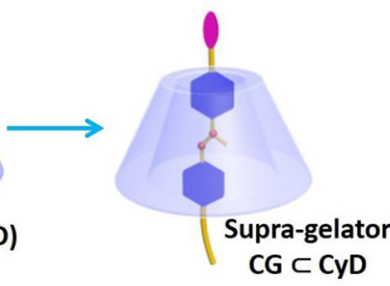

CG $\subset$ CyD

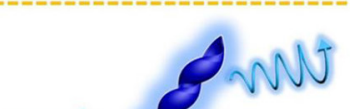

Enhanced CD \& CPL

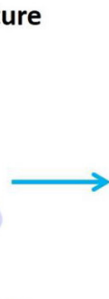

D

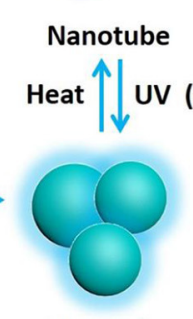

Nanosphere
C

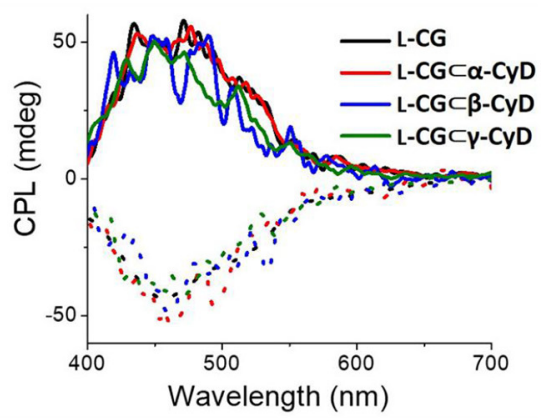

D

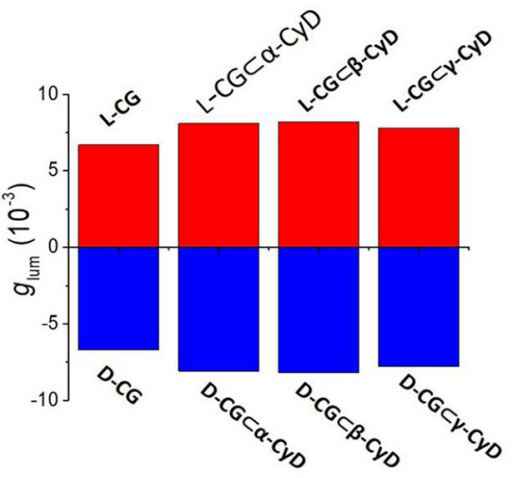

FIGURE 4 | (A) Molecular structure of hydrogelator CG and schematic formation of supra-gelator CG-CyDs. (B) Suggested gelation route of supra-gelator CG-CyDs (upper), UV irradiation induced Z-E isomerization in CG-CyD and the morphology change between nanotube and nanosphere (bottom). (C) CPL curves of CG and CG-CyDs hydrogels. (D) Glum values plot of CG and CG-CyDs hydrogels. The dashed lines refer to the counterparts of the D-configuration CG based gels. [CG] = $6.5 \mathrm{mM}$, [CG-CyD] = 6.5 mM. Reproduced with permission (Ji et al., 2019). Copyright 2019, Royal Society of Chemistry.
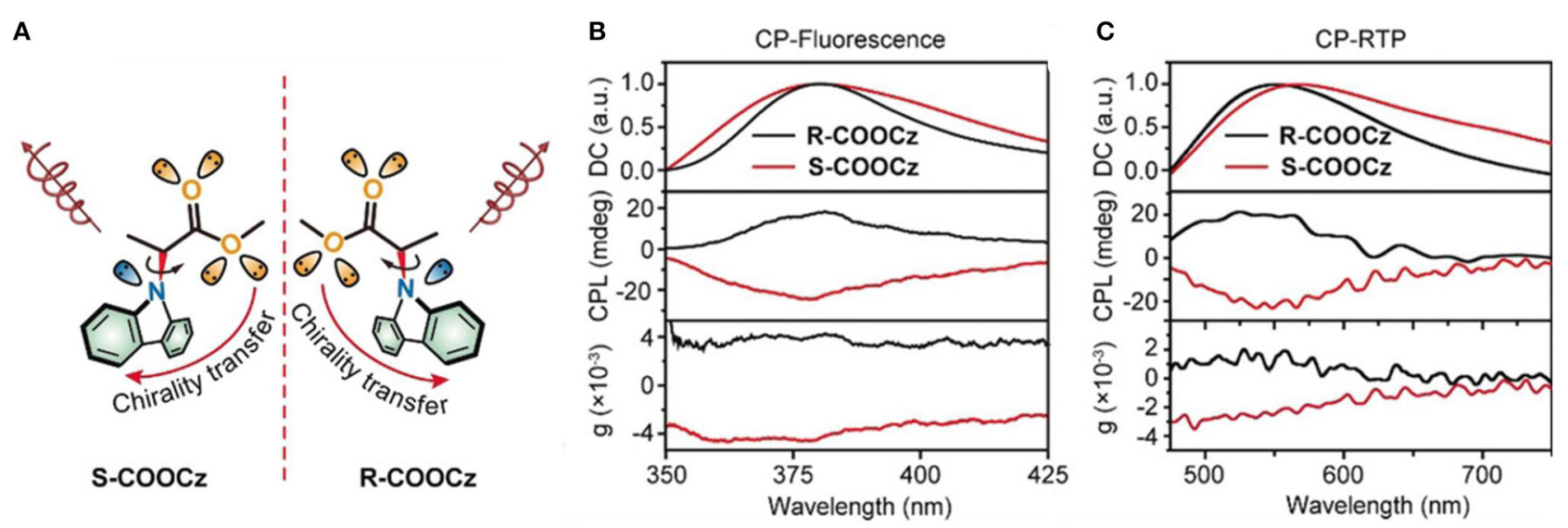

FIGURE 5 | (A) Molecular design of chiral CP-OURTP molecules (S- and R- COOCz). (B) CP-Fluorescence curves excited at $295 \mathrm{~nm}$. (C) CP-RTP curves excited at $365 \mathrm{~nm}$. Reproduced with permission (Li et al., 2020). Copyright 2020, John Wiley and Sons.

to the $\mathrm{Zn}^{2+}$-Salen unit. Addition of EDTA as a competitive $\mathrm{Zn}^{2+}$ binder can switch-off the CPL signal. Another example of $\mathrm{Zn}^{2+}$ coordinated complex with turn-on CPL in the farred region (wavelength: $700-850 \mathrm{~nm}, \Phi_{\mathrm{FL}}: 0.23$ ) was reported in 2018 (Ito et al., 2018). In this system, a pair of achiral benzo[a]phenanthrene-fused dipyrromethene ligands formed a helical structure upon coordination with Zinc(II) (Figure 7B), which showed strong exciton-coupled chiroptical responses in both ground state $\left(\mathrm{g}_{\mathrm{abs}} \sim 0.20\right)$ and the excited state (glum $\sim 0.022$ ). Notably, the asymmetrical luminescence factor was the largest yet reported among rare-earth- and precious-metal-free small molecules.

Besides the on-off switch, a switch of the CPL emission colors were also reported for $\mathrm{Zn}$ (II) complexes in case of imidazole 


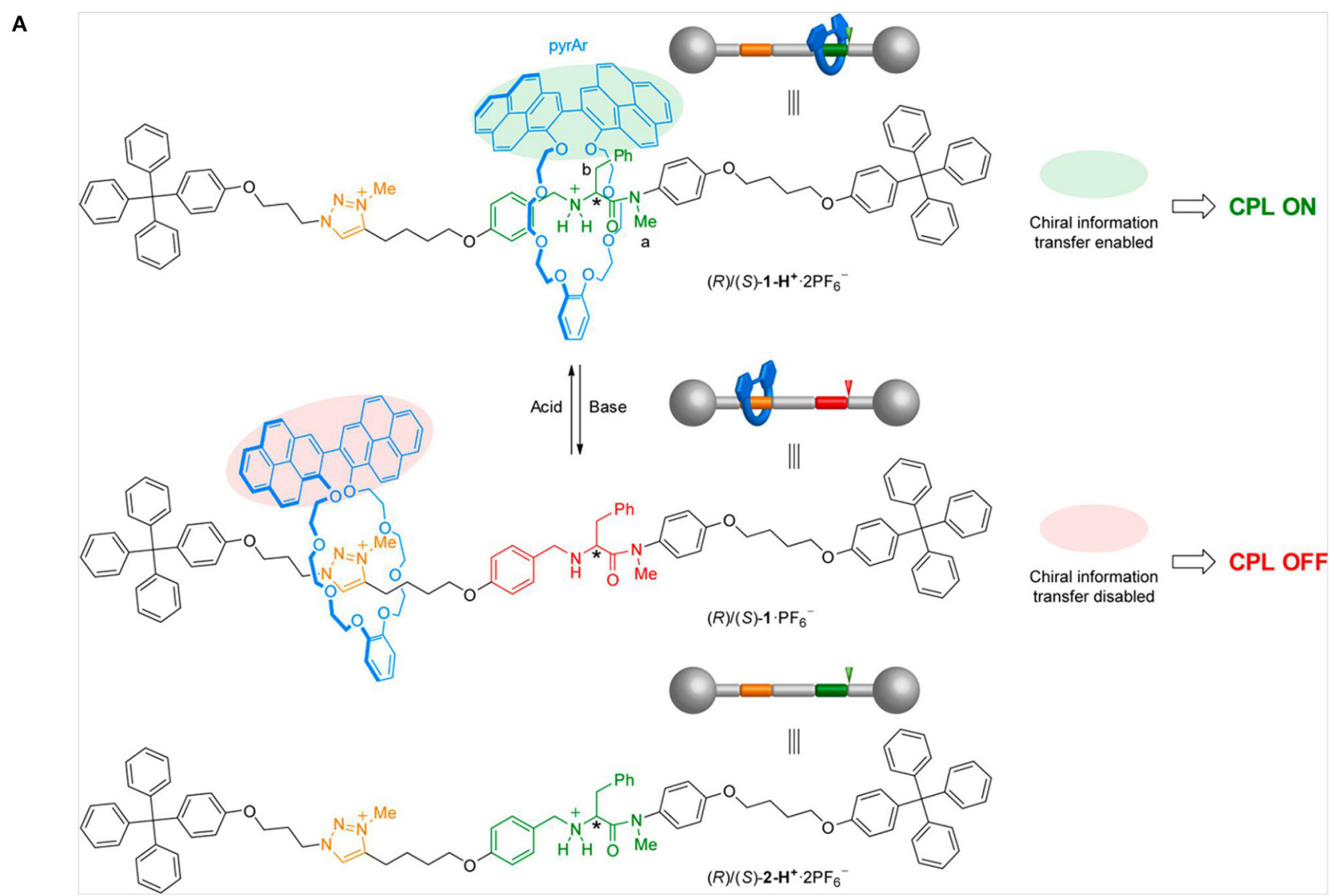

B
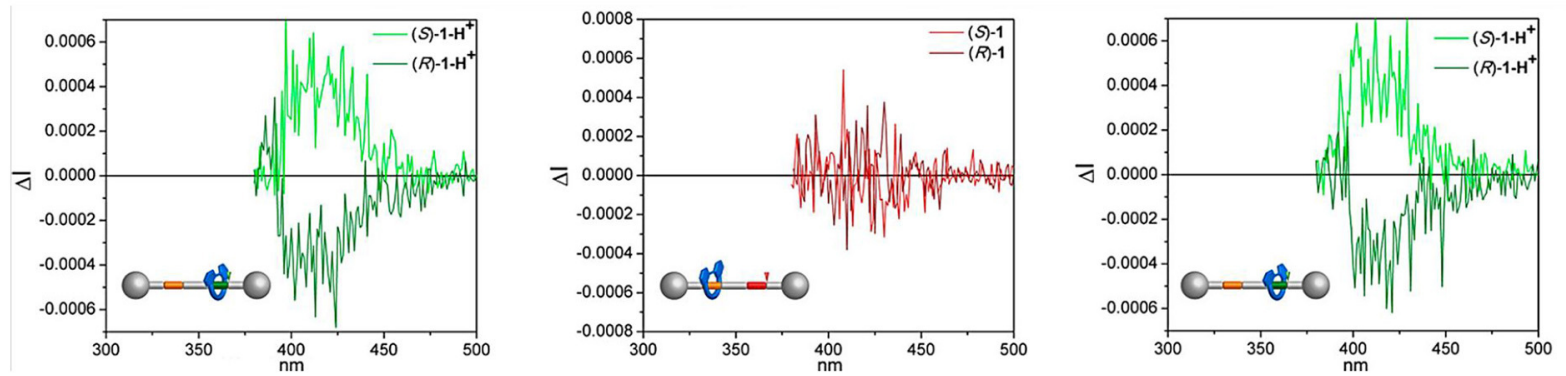

FIGURE 6 | (A) On-off CPL switching of rotaxanes $(\mathrm{R}) /(\mathrm{S})-1-\mathrm{H}^{+} \cdot 2 \mathrm{PF}_{6}$ by acid/base- controlled chirality transfer from the thread to the pyrene containing macrocycle. (B) $\mathrm{CPL}$ spectra of $1-\mathrm{H}^{+} \cdot 2 \mathrm{PF6}^{-}$(left), 1.PF6- (middle), and 1- $\mathrm{H}^{+}$(right), obtained by protonation of 1.PF6 ${ }^{-}$with $\mathrm{CF}_{3} \mathrm{CO}_{2} \mathrm{H}_{\text {in }} \mathrm{CHCl}_{3}$, condition: normalized $\Delta \mathrm{l}$ scale, $\lambda_{\text {exc }}=355 \mathrm{~nm}$, ca. $1 \times 10^{-5}$ M. Reproduced with permission (David et al., 2019). Copyright 2019, American Chemical Society.

or histidine ligand, which originated from changes in their compositions or their assembly behavior. CPL activities of pyrene bridged dual chiral imidazole units $\left(\mathrm{L}^{\mathrm{S}}\right)$ were found to be dependent on the ratio of ligand to $\mathrm{Zn}^{2+}$ (Imai and Yuasa, 2019). When the molar ratio of $\left[\mathrm{Zn}^{2+}\right] /\left[\mathrm{L}^{\mathrm{S}}\right]_{0}$ was $<0.33$, a complexation with the formula of $\left(\mathrm{Zn}_{1} \mathrm{~L}_{3}\right) \mathrm{n}$ appeared with blue pyrene monomer emission ( $445 \mathrm{~nm}, 467 \mathrm{~nm}$ ), and no CPL signal was detected. When the molar ratio of $\left[\mathrm{Zn}^{2+}\right] /\left[\mathrm{L}^{\mathrm{S}}\right]_{0}$ increased to $0.33-0.67$, a $\left(\mathrm{Zn}_{2} \mathrm{~L}_{3}\right) \mathrm{n}$ complex formed that showed yellow emission $(535 \mathrm{~nm})$ (Figure 7C). The CPL signal was switched on, showing good asymmetrical behavior $\left(\left|g_{\text {lum }}\right| \sim 0.01\right)$ and emission quantum yield ( $\left.\Phi_{\mathrm{FL}} \sim 0.10\right)$. By contrast, the ligand with L- chirality did not show a similar CPL switch. Pyrene-conjugated L-histidine assembled into nanofibers and formed gels in a mixture of EtOH/ $\mathrm{H}_{2} \mathrm{O}$ (v/v 1:4), which exhibited right-handed CPL $(500 \mathrm{~nm})$. After complexation with $\mathrm{Zn}^{2+}$, the newly formed histidine-based penta-coordinated $\mathrm{Zn}$ (II) complex assembled into nanospheres, and the gel collapsed to form a suspension (Niu et al., 2019). Accordingly, the $\pi$ stacking of the pyrenes unit shifted from a T-shaped to a nearly paralleled arrangement, the related CPL signal shifted from the excimer emission to the monomer emission, and the CPL handedness was inverted from 
A

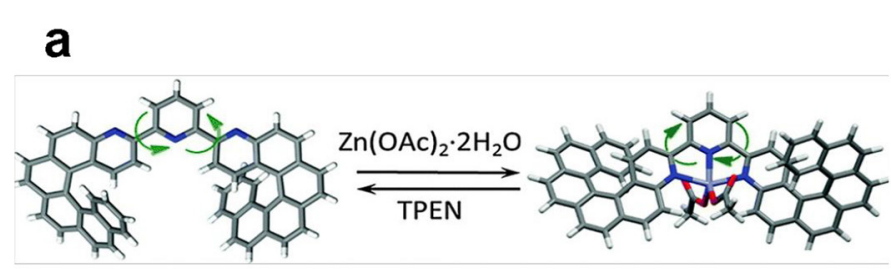

B

a

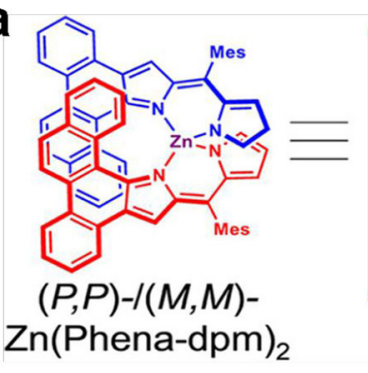

b

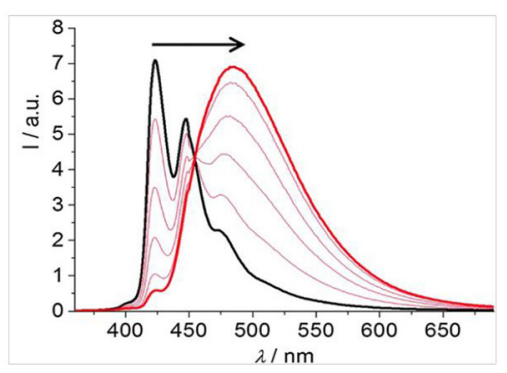

b

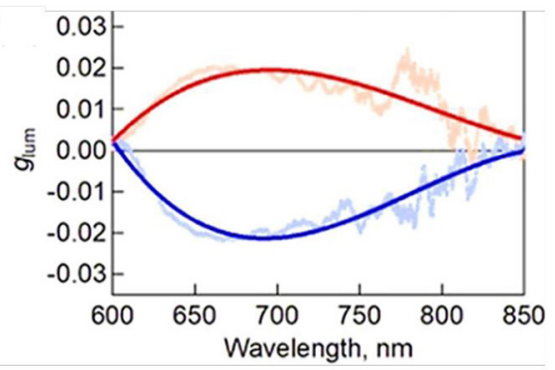

b

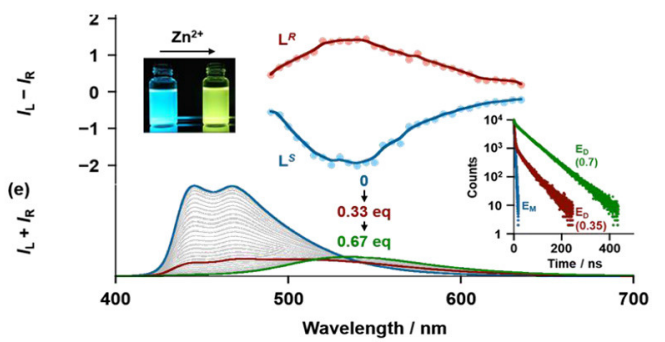

FIGURE 7 | (A) (a) Reversible Zn(II) complexation-decomplexation process of (P,P)-1 upon addition of Zn(OAc) 2 and TPEN. (b) Complexion-related fluorescence change of $(P, P)-1\left(\lambda_{e x}=350 \mathrm{~nm}, 2.2 \times 10^{-5} \mathrm{M} \mathrm{in} \mathrm{CH}_{2} \mathrm{Cl}_{2}\right.$. (B) (a) Zinc(II) helicate (Zn(Phena-dpm) $)$ formed by coordinating with two achiral phenanthrene-fused dipyrromethene ligands. (b) Smoothed glum curves of M,M (red line) and P, P enantiomer (blue line) measured in toluene ( $\lambda_{\text {ex }}=580 \mathrm{~nm}$ ), respectively. (C) (a) Chemical structures of chiral ligands $L^{R}$ and $L^{S}$. (b) Emission color change (upper left) and emission spectral change (lower left, $\lambda_{e x}=380 \mathrm{~nm}$ ) of $L^{S}$ toward $Z n^{2+}, C P L$ of $L^{R}$ and $\mathrm{L}^{\mathrm{S}}$ (middle) $\left(2.0 \times 10^{-5} \mathrm{M}\right)$ in the presence of $\mathrm{Zn}^{2+}\left(1.4 \times 10^{-5} \mathrm{M}\right)$, emission decay profiles of $\mathrm{L}^{\mathrm{S}}\left(2.0 \times 10^{-5} \mathrm{M}\right)$ (right) without $\mathrm{Zn} \mathrm{n}^{2+}$ (blue), with low ratio of $\mathrm{Zn}^{2+}(7.0$ $\left.\times 10^{-6} \mathrm{M}(\mathrm{red}), \lambda_{\mathrm{em}}=446 \mathrm{~nm}\right)$, and with high ratio of $\mathrm{Zn}^{2+}\left(1.4 \times 10^{-5} \mathrm{M}\right.$ (green), $\left.\lambda_{\mathrm{em}}=535 \mathrm{~nm}\right)$. (A) Reproduced with permission (Isla et al., 2016). Copyright 2016 , Royal Society of Chemistry). (B) Reproduced with permission (Ito et al., 2018). Copyright 2018, John Wiley and Sons. (C) Reproduced with permission (Imai and Yuasa, 2019). Copyright 2019, Royal Society of Chemistry.

right handedness to left handedness (Figure 8A). Such emission switch of wavelength and handedness was reversible by removing the $\mathrm{Zn}(\mathrm{II})$ ions with the strong chelator EDTA.

$\mathrm{Ni}^{2+}$ and $\mathrm{Al}^{3+}$ worked similarly through complexation to modify both the assembly behavior and CPL properties of organic molecules. A chiral phenylalanine-derived hydrogelator and a pyridine modified achiral coumarin co-assembled to form chiral gels, showing CPL at around $450 \mathrm{~nm}\left(\mathrm{~g}_{\text {lum }} \sim 10^{-2}\right)$ with handedness being dependent on the position of the pyridine nitrogen atom (Wang et al., 2019). The introduction of $\mathrm{Ni}^{2+}$ removed the influence of the $\mathrm{N}$-position and resulted in all the isomers producing the same P-helix and left-handed emission (Figure 8B). The different handedness was inferred to result from different dominant hydrogen-bonding interactions, including carboxylic acid-pyridine hydrogen bonds and amide hydrogen bonds. Thus, CPL with opposite handedness was obtained by tuning the nitrogen position and the metal additive. Aluminum ion $\left(\mathrm{Al}^{3+}, \mathrm{AlCl}_{3}\right.$, ethanol) (Jin Q. et al., 2018) was found to turn-on the CPL of glutamide-derived amphiphilic Schiff base containing a 1-hydroxyl-2-naphthaldehyde group. Inhibition of photon-induced electron transfer (PET) or excited-state induced proton transfer (ESIPT) enhanced the blue emission and specific chirality transfer from the ligand to the chromophore resulted in observable CPL emission ( $465 \mathrm{~nm},\left|\mathrm{~g}_{\text {lum }}\right| \sim 6.21 \times 10^{-4}$ ).

Along with the coordination mechanism, metal ion also affected the assembly through carbophilic and oxophilic interactions. For instance, CPL activity of ortho-oligo(phenylene)ethylene (OPE) foldmers can be tuned by adding either carbophilic $\mathrm{Ag}^{+}$or oxophilic $\mathrm{Ca}^{2+}, \mathrm{Sc}^{3+}$, and $\mathrm{Zn}^{2+}$ ions. A series of ortho-oligo-(phenylene)ethylene (OPE) foldmers were confined into chiral helical structure by introducing enantiopure 2,3-dihydroxybutane diethers, exhibiting strong CPL responses (glum values up to $1.1 \times 10^{-2}$ ) and a low but acceptable fluorescence efficiency $\left(\Phi_{\mathrm{FL}} \sim 0.069\right.$ in $\mathrm{CH}_{2} \mathrm{Cl}_{2}$ ). 


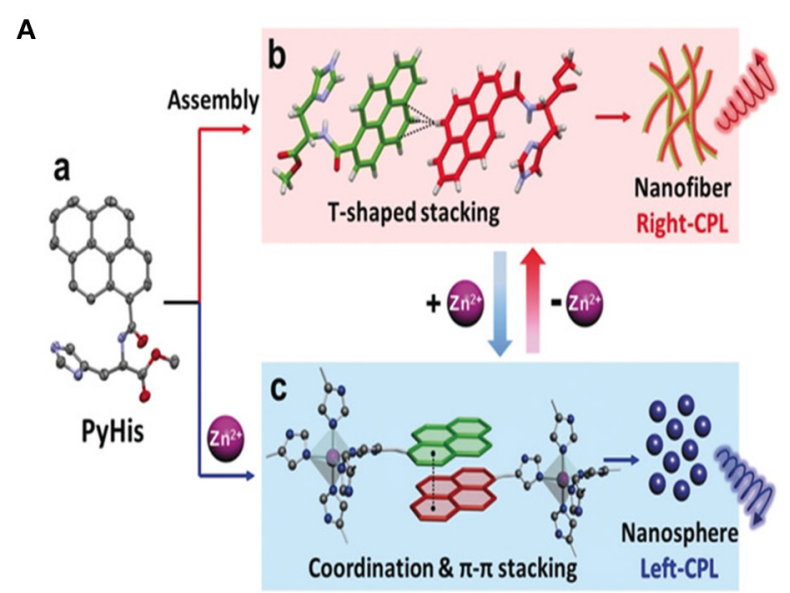

B

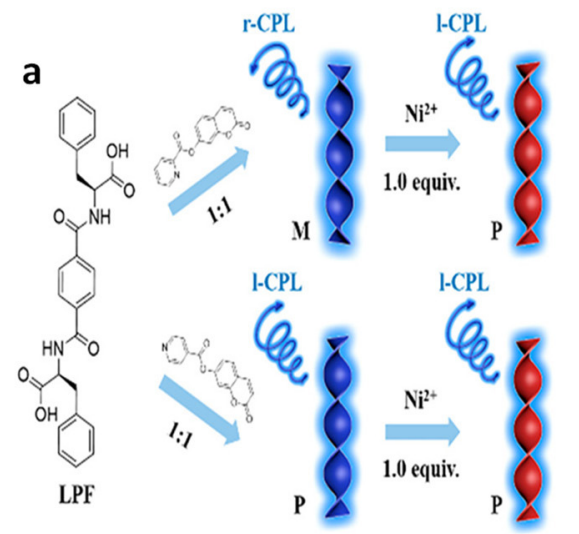

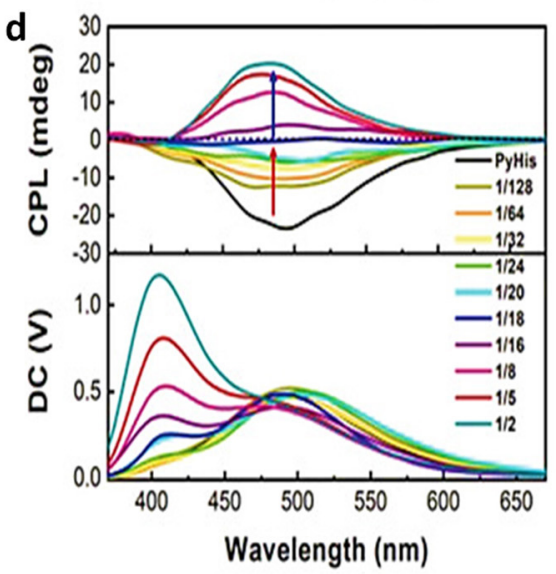

b
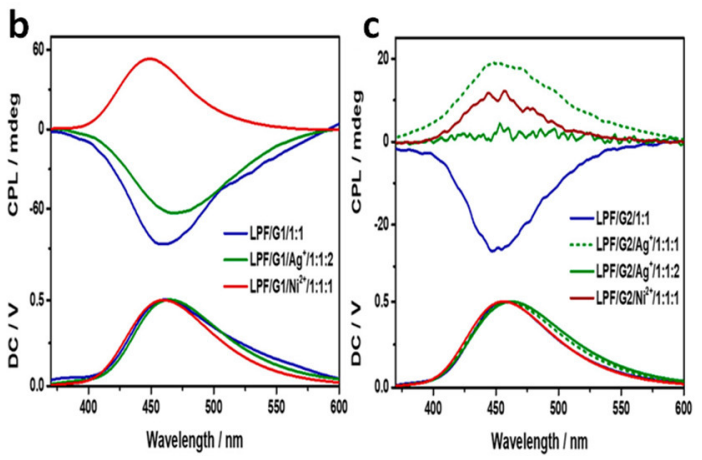

FIGURE 8 | (A) Schematic illustration about assembly changes and CPL changes of the chiral gelator PyHis toward Zn²+. (a) Single-crystal structure. (b) T-shaped stacking of pyrenes in PyHis nanofibers, showing right-handed CPL. (c) $\pi-\pi$ stacking of pyrenes with distorted triangular bipyramid $\left[\mathrm{Zn}\left(\mathrm{PyH} \mathrm{H}_{5}\right]^{2+}\right.$ complex, which formed nanospheres with increasing amount of $\mathrm{Zn}^{2+}$ and showed left-handed CPL. (d) CPL spectra change of I-PyHis gel upon increased amount $\mathrm{Zn}{ }^{2+}$ $\left(\lambda_{\text {ex }}=330 \mathrm{~nm}\right)$. (B) Schematic illustration of CPL behaviors dependent on pyridyl-N location of coumarin derivatives, and further $\mathrm{Ni}^{2+}$ (a). $\mathrm{PL}$ and fluorescence spectra of pyrenes of LPF/G1 (b), LPF/G2 (c) hydrogels with different amount of $\mathrm{Ag}^{+}$or Ni²+ ions, excited at $320 \mathrm{~nm}$. (a) Reproduced with permission (Niu et al., 2019 ). Copyright 2019, John Wiley and Sons. (b) Reproduced with permission (Wang et al., 2019). Copyright 2019, American Chemical Society.

When $\mathrm{Ag}^{+}$was introduced, its strong affinity toward alkyne units resulted in its confinement within the OPE cavity. As a result, the conformation changed from a helical structure to a planar-like structure, which resulted in a decrease of glum values by up to one order of magnitude (Morcillo et al., 2016). Recovery of the asymmetrical optical properties can be achieved by adding a stoichiometric amount of competitive $\mathrm{CH}_{3} \mathrm{CN}$ to extract the confined $\mathrm{Ag}^{+}$ions. When such an OPE helical skeleton was functionalized at both the $\mathrm{C} 1$ and $\mathrm{C} 2$ stereogenic positions with a pyrene unit, dual wavelength $\mathrm{CPL}$ emission in the blue (centered at $400 \mathrm{~nm}$ ) and green (centered at $500 \mathrm{~nm}$ ), originated from the OPE helicate and pyrene excimer located, respectively (Figure 9). Similar CPL silencing from the OPE unit upon carbophilic association with $\mathrm{Ag}^{+}$ion was observed (Reine et al., 2018), while the CPL signal from the pyrene units was retained. With careful screening of the bridge between the chiral 2,3-dihydroxybutane diethers moiety and the pyrene units, the CPL signal $[\Delta \mathrm{I}(400 \mathrm{~nm}) / \Delta \mathrm{I}(500 \mathrm{~nm})]$ of one foldmer
$\left[(\mathrm{P}, 1 \mathrm{~S}, 2 \mathrm{~S})-2, \mathrm{CH}_{2}\right.$ bridge $]$ acted as a ratiometric probe toward $\mathrm{Ag}(\mathrm{I})$ concentration.

When the OPE unit was modified with sulfoxides at the end positions, oxophilic metal cations $\left(\mathrm{Ca}^{2+}, \mathrm{Sc}^{3+}\right.$, and $\mathrm{Zn}^{2+}$ ) interacted with oxygen atoms, promoted the folding of OPE to form helical conformation, and turned on the chiroptical properties (Reiné et al., 2018). Meanwhile, the helical conformation avoided aggregation induced emission quenching of the fluorophore itself. Consequently, the metal complexes exhibited both glum values and high $\Phi_{\mathrm{Fl}}$. A representative example was the $\mathrm{Sc}^{3+}$ complex, of which the glum and $\Phi_{\mathrm{Fl}}$ were $-7.1 \times 10^{-3}$ and 0.38 , respectively.

\section{pH}

Manipulating $\mathrm{pH}$ value has been demonstrated to be a broadly applicable tool to tune both the wavelength and the intensity 

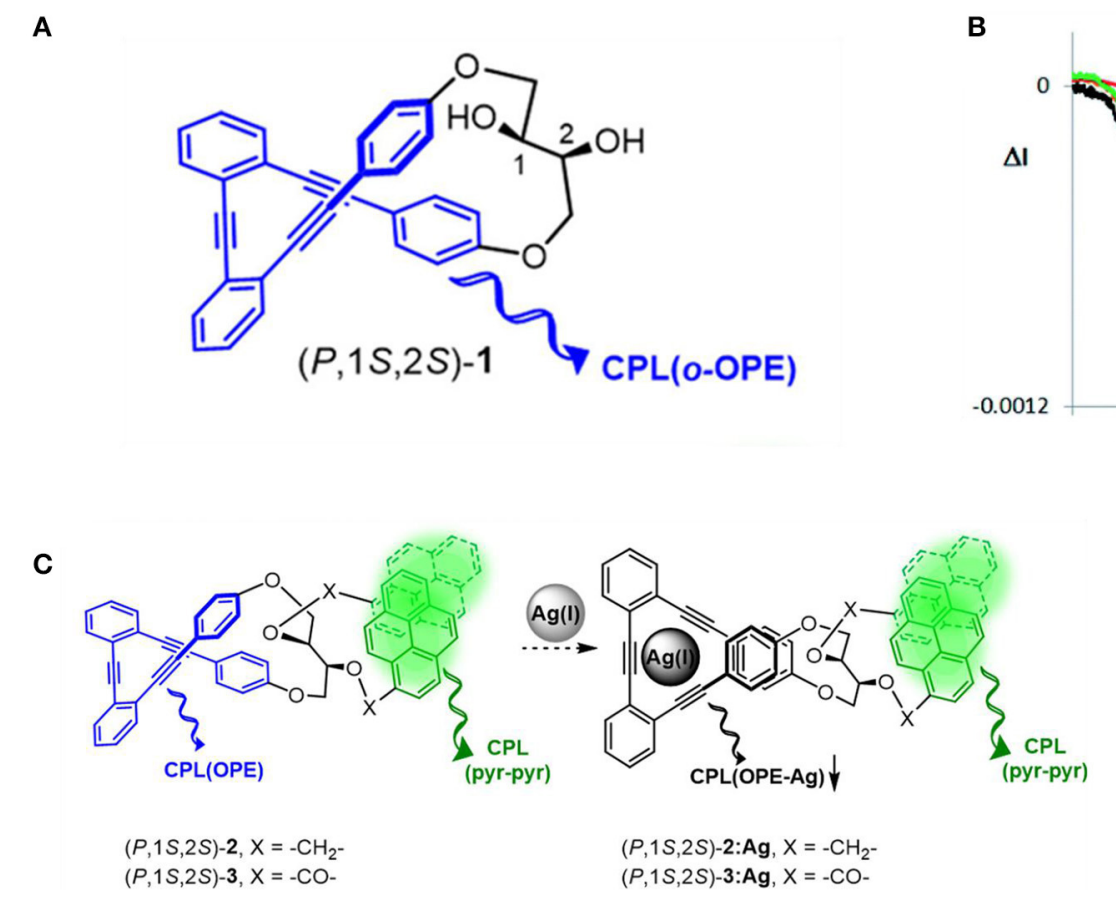

B

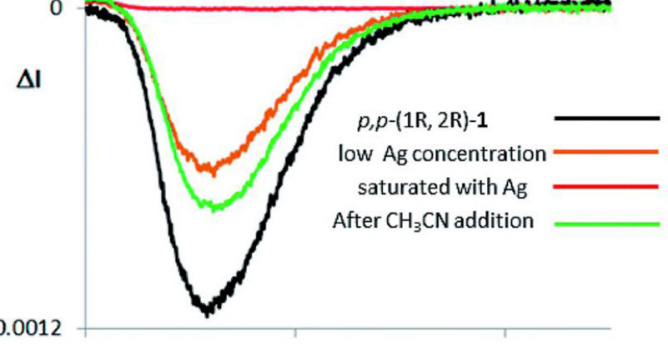

D

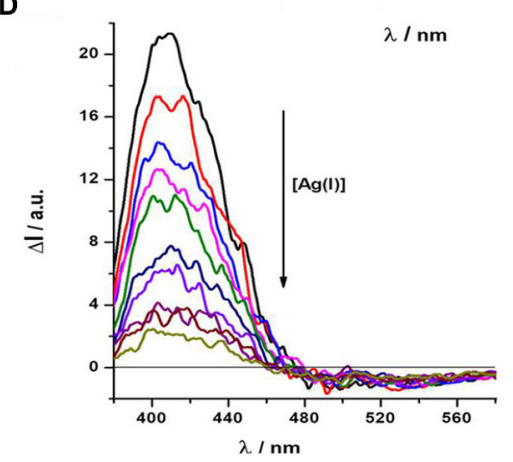

FIGURE 9 | (A) Chemical structure of helical oligo(phenylethylene) $(P, 1 \mathrm{~s}, 2 \mathrm{~s})-\mathbf{1}$. (B) CPL titration curves with increasing amount of $\mathrm{AgBF}_{4}$ until saturation, and with following addition of $\mathrm{CH}_{3} \mathrm{CN}$. (C) Schematic mechanism of a $(P, 1 \mathrm{~s}, 2 \mathrm{~s})-1$ based ratiometric $\mathrm{CPL}$ probe based. (D) CPL titration curves of $(P, 1 \mathrm{~s}, 2 \mathrm{~s})-2$ with increasing amount of $\mathrm{AgBF}_{4}$. (A,B) Reproduced with permission (Morcillo et al., 2016). Copyright 2016, Royal Society of Chemistry. (C,D) Reproduced with permission (Reine et al., 2018). Copyright 2018, American Chemical Society.

of CPL. The wavelength shift was achieved by protonation of N-heterocycle-containing chromophores or deprotonation of acidic protons. The intensity tune was exemplified by tuning the competing non-emissive pathways. Moreover, both changes could be facilely reversed by reverting to the original $\mathrm{pH}$ by adding appropriate amounts of acid or base. The CPL color of benzimidazole-fused [5] carbohelicene ([5]HeliBI) (Figure 10A) can be switched from yellow $(570 \mathrm{~nm})$ to red $(650 \mathrm{~nm})$ by protonation with trifluoroacetic acid to form $\left(\mathrm{H}^{+}-[5] \mathrm{HeliBI}\right)$ (Sakai et al., 2016). Both yellow and red CPL show high glum values in the $\mathrm{CH}_{2} \mathrm{Cl}_{2}$ solution, which were estimated to be $\sim 9.45 \times 10^{-3}$ and $\sim 5.92 \times 10^{-3}$, respectively. Moreover, the process was reversible by deprotonation with pyridine. Similar reversible $\mathrm{CPL}$ emission tuned by acid/base addition $\left(\mathrm{HBF}_{4}\right.$, $\mathrm{Na}_{2} \mathrm{CO}_{3} / \mathrm{NEt}_{3}$ ) was observed for both P- and M- 3-(2-pyridyl)4-aza[6] helicene (Saleh et al., 2015). Bathchromic emission from 426 to $590 \mathrm{~nm}$ was observed after dual protonation, while the quantum yield, lifetime, and glum value $\left(\sim 10^{-3}\right)$ remained almost the same (Figure 10B). For diaza [4] helicene functioned with a carboxylic acid group, lowering the $\mathrm{pH}$ from 7.3 to 0.4 resulted in protonation of the zwitterion form to the protonated from (Pascal et al., 2016), and the fluorescence emission was shifted from $709 \mathrm{~nm}$ (acetonitrile, QY 0.01\%) for to $654 \mathrm{~nm}$ (QY $\sim 0.29 \%$ ) (Figure 10C). Differently, no CPL signal was detected for the former, while CPL signal $(600 \mathrm{~nm})$ was turned on for the later with a glum value of $\sim 5 \times 10^{-4}$. Thus, an off-on CPL switch was achieved by increasing/lowering the acidity of the system. Turn-on of CPL by lowering $\mathrm{pH}$ was also observed for a co-assembled gel of achiral perylene bisimide dye and N,N'bis(octadecyl)-L/D-Boc glutamic diamide gelator (Figure 10D), which was a result of chiral transfer from the chiral part to PBI and inhibited photon induced charge transfer in the PBI unit (Han D. et al., 2018). The CPL sign was the same as the chirality of the chiral gelator, and the bright yellow emission was centered at $558 \mathrm{~nm}$. The glum was calculated to be a moderate $\sim 9 \times 10^{-3}$. When the co-gel was exposed to a basic atmosphere, such as ammonia, the CPL signal could be reversibly switched off. Thus, an on-off CPL switch was obtained by applying the co-gel to alternating acidic and basic conditions.

Besides the above-mentioned cases using Lewis acid/base and Brönsted acid/base activation, a photo-acid functionalized dye also showed $\mathrm{pH}$ dependent emission behavior. In the co-assembled gel of non-emissive photoacid 8-hydroxy-1,3,6pyrenetrisulfonate (HPTS) and chiral amino-terminated dialkyl glutamide (LG) (Figure 11), the emission wavelength and the glum value was modulated by the composition of solvent or acid/base additive (Fan et al., 2019). A mixed molar ratio of 1:10 of HPTS:LG assembled in DMF: $\mathrm{H}_{2} \mathrm{O}$ resulted in nanotube structure, with the components arranged in a lamellar motif. CD signals in the same range of absorption $(250-450 \mathrm{~nm})$ retained the chirality from the gelator, which proved that chirality transfer occurred from the gelator to the photoacid. Upon excitation in 
A

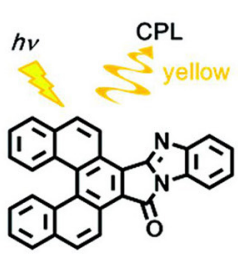

[5]HeliBI
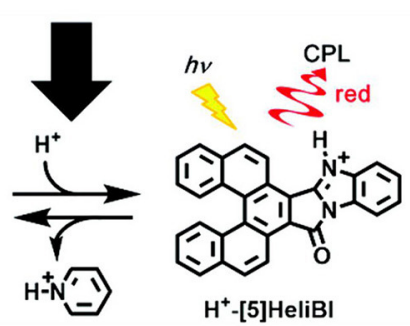

B

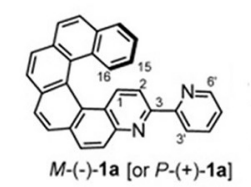

$\mathrm{Na}_{2} \mathrm{CO}_{3} \uparrow \downarrow$ "HBF"

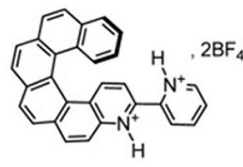

$M-(-)-\left[1 \mathrm{a}, 2 \mathrm{H}^{+}\right]\left[2 \mathrm{BF}_{4}-\right]$

[or $P-(+)-1\left[1 \mathrm{a}, 2 \mathrm{H}^{+}\right]\left[2 \mathrm{BF}_{4^{-}}\right]$
C
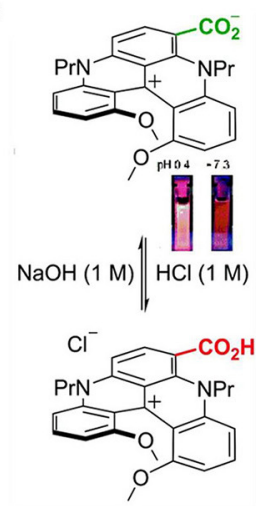

D

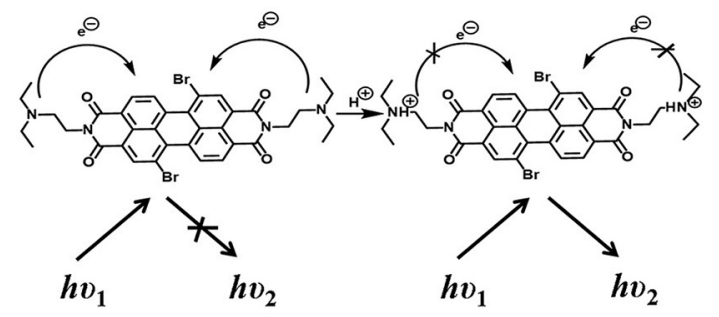

Fluorescence

FIGURE 10 | (A,B) pH induced switchable CPL based on pyridine N-atom. (C) deprotonation of aromatic carboxylic acid. (D) protonation of tertiary amine. (A) Reproduced with permission (Sakai et al., 2016). Copyright 2016, Royal Society of Chemistry. (B) Reproduced with permission (Saleh et al. 2015). Copyright 2015, John Wiley and Sons. (C) Reproduced with permission (Pascal et al., 2016). Copyright 2016, Royal Society of Chemistry. (D) Reproduced with permission (Han D. et al., 2018). Copyright 2018, Royal Society of Chemistry.

a proton-accepting environment (mixed solvent of DMF: $\mathrm{H}_{2} \mathrm{O}$ ratio $<7: 3$, or basic condition), excited-state induced proton transfer from the photoacid to the environment shifted the CPL signal from $420 \mathrm{~nm}$ (pristine HPTS) to $520 \mathrm{~nm}$ (deprotonated HPTS). Meanwhile, the $g_{\text {lum }}$ of the green emission was increased to $10^{-3}$.

\section{CONTROLLED ASSEMBLY SWITCHABLE BY SOLVENT, TEMPERATURE, AND OTHER MISCELLANEOUS FACTORS}

CPL materials usually showed higher glum values from aggregates or assembled states than from the monomers, and manipulation of the assembly behavior resulted in tunable CPL performances. Broadly applicable manipulating factors included solvent, temperature, and mechanical forces.

Solvents with varied polarity, hydrogen-bonding capabilities and solubility have been used to tune the electronic structure through intramolecular charge transfer (ICT), the assembly behaviors, and the formation of excimers, respectively. Modulating the intramolecular charge transfer process of axial chiral triarylboranes resulted in switchable CPL behaviors. For 2,2'-bis(diphenylamino)-6,6' -bis(dimesityl-boryl)-1, $1^{\prime}$ binapthyl with a D- $\pi$-A structure (Sun Z. et al., 2019), increasing solvent polarity from cyclohexane $(455 \mathrm{~nm})$ to $\mathrm{MeCN}(521 \mathrm{~nm})$ showed an obvious red-shifted emission from 440 to $512 \mathrm{~nm}$ (Figure 12). Correspondingly, reversal of CPL sign was observed for the $(+)$-isomer in cyclohexane (negative signal) and in $\mathrm{MeCN}$ (positive signal). Similar sign inversion was also detected by using an excess amount of fluoride ions $\left(\mathrm{F}^{-}\right)$, which complexed with the boron atoms to greatly enhance the emission intensity and asymmetry $\left(\left|g_{\text {lum }}\right| \sim 10^{-2}\right)$. Handedness reversion by changing solvents was also observed due to reversal of the orientation of the helix. For a random polymer containing achiral fluorescent 5,7-bis(4-methyloxyphenyl)quinoxaline and chiral units modified with (S)-3-octyloxymethyl groups (Nishikawa et al., 2017), solvent change from n-octane to cyclooctane resulted in conformation change of the polymer from pure M- to P-helical, and the correspondent $\mathrm{CPL}$ shifted from right handedness to left handedness (Figure 13A). Moreover, the change of conformation was determined only by the chiral moiety, and the emission color can be tuned by modifying the luminescent part with different substituents. Thus, the polymer can be tuned orthogonally to prepare CPL materials with convertible handedness and variable emission colors. Furthermore, solvent tunable handedness was achieved for pyrene incorporated axially chiral 2-hydroxy 3, 3'-dimethylbinathyls with carefully designed substituents (Figure 13B). Highly polarized negative excimer emission in non-polar toluene $\left(538 \mathrm{~nm}, \mathrm{~g}_{\text {lum }} \sim-0.012\right)$ was reversed to right-handedness in polar DMSO $(520 \mathrm{~nm}$, glum $\sim 0.012$ ) (Takaishi et al., 2020). The sign switch was attributed to the reduced intermolecular H-bonding in the polar solvents and corresponding lower population of the left-handed excimer. This hypothesis was confirmed further by lowering the temperature. This resulted in the stronger negative emission being observed in toluene and lower positive emission being observed in acetone.

Along with switchable CPL behaviors in pure solvent, a ratio change between good solvent and poor solvent (mixture of THF and $\mathrm{H}_{2} \mathrm{O}$ ) has also been reported to produce tunable CPL. For a 1,8-naphthalimide fluorophore linked with chiral 1,2-diaminocyclohexane (DACH) (Sheng et al., 2016), excimertype CPL with large glum $\left(\sim 10^{-2}\right)$ was observed in THF or mixture of $\mathrm{H}_{2} \mathrm{O}$ and THF with $<90 \%$ water. Upon increasing the water content above $90 \%$, the assembly changed from an irregular form to an ordered aggregate, and the CPL sign was reversed. Similar THF/water ratio dependent assembly and CPL performance were observed for R- or S-SPAn (Ma K. et al., 2019). With increasing water ratio, the orderly aggregates changed from $0 \mathrm{D}$ nanoshperes ( $\mathrm{THF} / \mathrm{H}_{2} \mathrm{O} \sim 50: 50$ ), $2 \mathrm{D}$ flake (THF/ $\mathrm{H}_{2} \mathrm{O} \sim 85 \%$ ) to $3 \mathrm{D}$ nanoflakes (THF/ $\mathrm{H}_{2} \mathrm{O} \sim 90 \%$ ). 

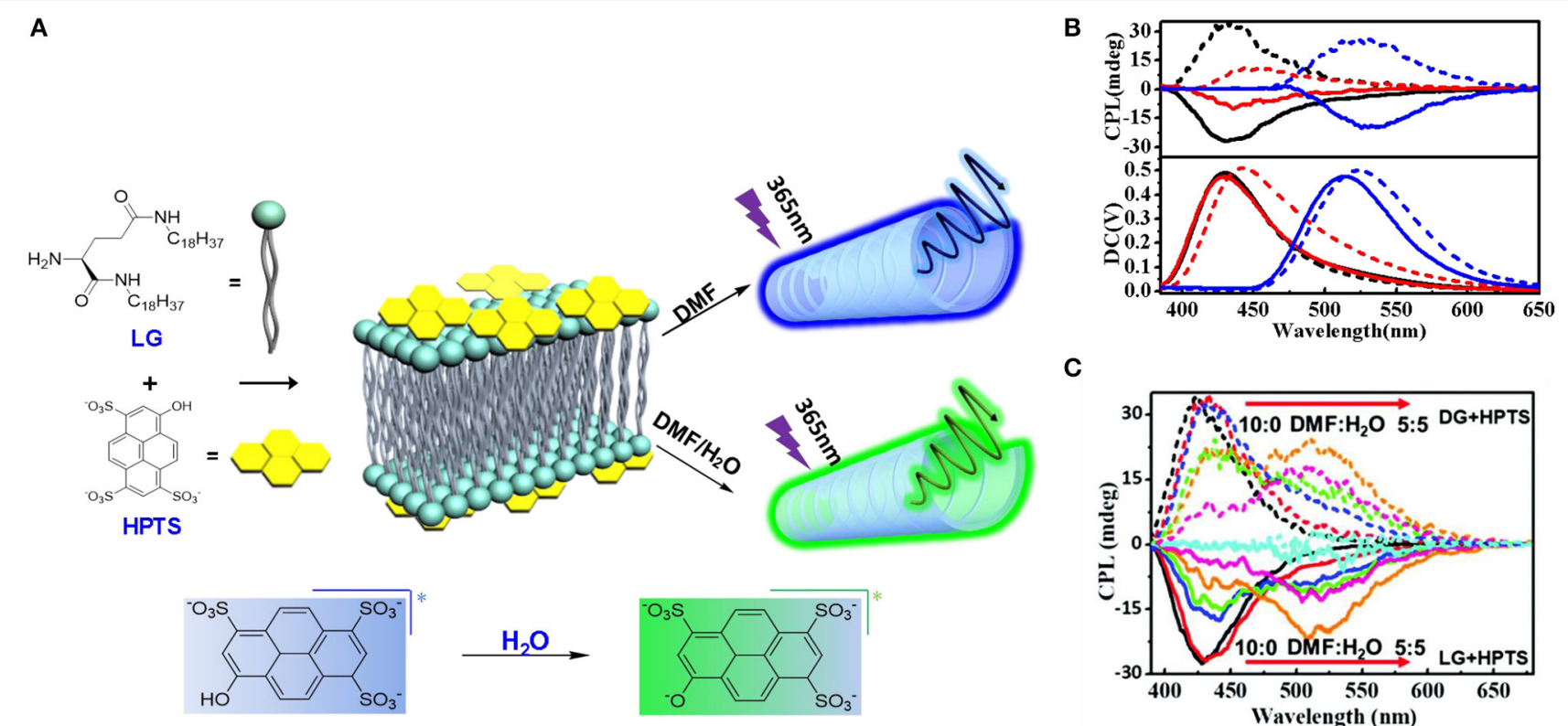

C

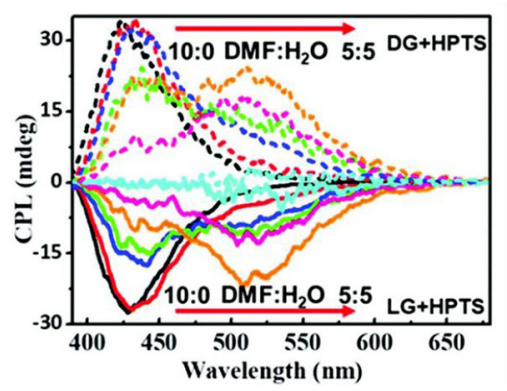

FIGURE 11 | (A) Chemical structure of $L G$ and HPTS, and the schematic demonstration about CPL dependence on solvent by deprotonation (RO-). (B) CPL spectra of $L G / H P T S$ (DMF/ $\mathrm{H}_{2} \mathrm{O}=9: 1$ ) gels (black line) and LG/HPTS gels with acid (red line) and base (blue line). Solid lines refer to LG/HPTS and dotted lines represent the DG/HPTS system. (C) CPL spectra of LG/HPTS (dash) and DG/HPTS (line) supramolecular gels in mixed solvents of N,N-Dimethylformamide (DMF) and water ( $\mathrm{H}_{2} \mathrm{O}$ ). The measurements were carried out in the solutions with a concentration of $\sim 1.23 \times 10^{-4} \mathrm{M}$ at room temperature, under the excitation of $370 \mathrm{~nm}$. Reproduced with permission (Fan et al., 2019). Copyright 2019, Royal Society of Chemistry.

Meanwhile, the emission wavelength shifted from $420 \mathrm{~nm}$ ( $\Phi_{\mathrm{FL}}$ : $0.6), 432 \mathrm{~nm}\left(\Phi_{\mathrm{FL}}: 0.04\right)$ to $460 \mathrm{~nm}\left(\Phi_{\mathrm{FL}}: 0.13\right)$. The related glum value increased from the value of $10^{-4}, 7.2 \times 10^{-3}$, to $2.9 \times 10^{-2}$, inferring favor of high $\mathrm{g}_{\text {lum }}$ with larger ordered structures.

The CPL behaviors were influenced by temperature through cooling to form ordered chiral assemblies or through heating to dissolve the assembly, which was utilized to tune either the CPL handedness or the emission wavelength. Upon lowering the temperatures, two-stage cooperative assembly of dithienogermole (DTG) molecules driven by dipole-dipole interaction of chiral phenylisoxazoles pendants was observed in methyl-cyclohexane $(\mathrm{MCH})$, including a first nucleation stage and a later elongation stage. Correspondingly, CPL signals with different emission wavelengths and inverted handedness were observed (Hirano et al., 2019). When the temperature was initially dropped from 40 to $20^{\circ} \mathrm{C}$, a weak positive CPL appeared at $566 \mathrm{~nm}$ (Figure 14). Further cooling to $10^{\circ} \mathrm{C}$ resulted in increased CPL at $566 \mathrm{~nm}$, and a new negative signal at $472 \mathrm{~nm}$ was observed. After further cooling to $-10^{\circ} \mathrm{C}$, the positive signal disappeared, and only a negative signal at $514 \mathrm{~nm}$ was detected. Thus, the temperature dropping from 20 to $-10^{\circ} \mathrm{C}$ fully inverted a positive signal at $566 \mathrm{~nm}\left(\mathrm{~g}_{\text {lum }} \sim 8 \times 10^{-4}\right)$ to a negative signal at $514 \mathrm{~nm}$ (glum $\sim-3 \times 10^{-4}$ ). Similar sign change was also observed in the $\mathrm{CD}$ signals for both the $\mathrm{S}$ and R- enantiomers, which suggested the assembly behavior dominated the chirality in both the ground and excited states. Thus, chirality inversion was achieved by controlled assembly at different temperatures. Similarly, L-glutamide-functionalized phenyl anthracene (g-PA) showed solvent- and cooling-ratedependent CPL signals (Jintoku et al., 2015). In pure THF, no CPL signal was observed. In a mixture of $n$-hexane/THF (50:1), the organic gel showed clear excimer-type CPL signal at $526 \mathrm{~nm}$, and the glum value is $\sim 3.2 \times 10^{-3}$. Thus, the gel state enhanced chirality transfer from the L-glutamide unit to the excimer of anthracene. As the temperature elevated from 10 to $60^{\circ} \mathrm{C}$, excimer emission was changed to monomer emission $(426 \mathrm{~nm})$ with decreasing $\mathrm{g}_{\text {lum. }}$. Moreover, the slower the reversed cooling process, the higher ratio of the excimer $\mathrm{CPL}$ at $10^{\circ} \mathrm{C}$.

Moreover, CPL performance switched with mechanical triggers, and oxidation anions and co-assembled achiral isomers were reported. Mechanical mixing of difluoro-boron $\beta$-diketonate complexes with chiral amide ligands (DFB-Hexamide) triggered CPL sign inversion (Louis et al., 2019). For the crystalline state obtained from thermal annealing, strong emission appeared in the blue-green range ( $475 \mathrm{~nm}, \Phi_{\mathrm{FL}} \sim 0.10-$ 0.13 ), and the glum value reached the level of $\sim 10^{-2}$ (Figure 15). After applying a shearing stress, the CPL signs for the two signals at 450 and $550 \mathrm{~nm}\left(\Phi_{\mathrm{FL}} \sim 0.35\right)$ were inverted, and the glum value $(500-550 \mathrm{~nm})$ dropped to $3 \times 10^{-3}$. By referring to structural analogs and the fluorescence lifetime measurements, the signal at $450 \mathrm{~nm}$ was ascribed to the remaining microcrystals in the smeared sample, while the signal at $500-550 \mathrm{~nm}$ was assigned to the excimers. A CPL sign dependent on the amount of hypochlorite ion $\left(\mathrm{ClO}^{-}\right)$present was observed for a chiral gel composed of an achiral phenothiazine derivative and a gelating chiral glutamic lipid (PTD-Z) through step-wise oxidation of the sulfur atom in the phenothiazine ring (Gong et al., 2019). 
A
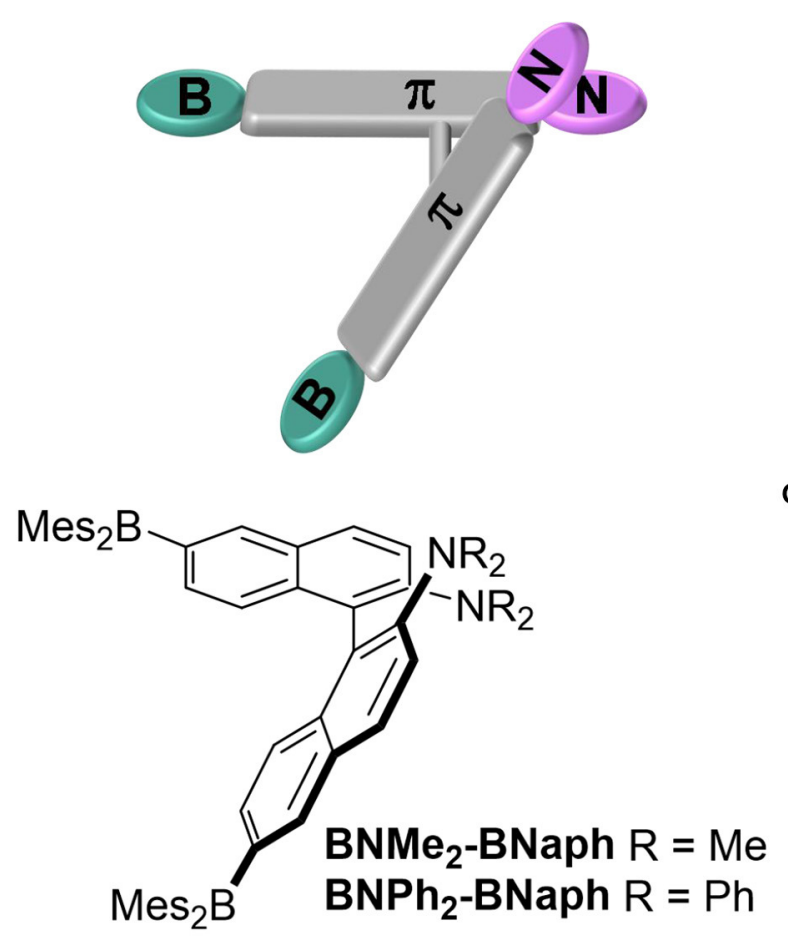

B

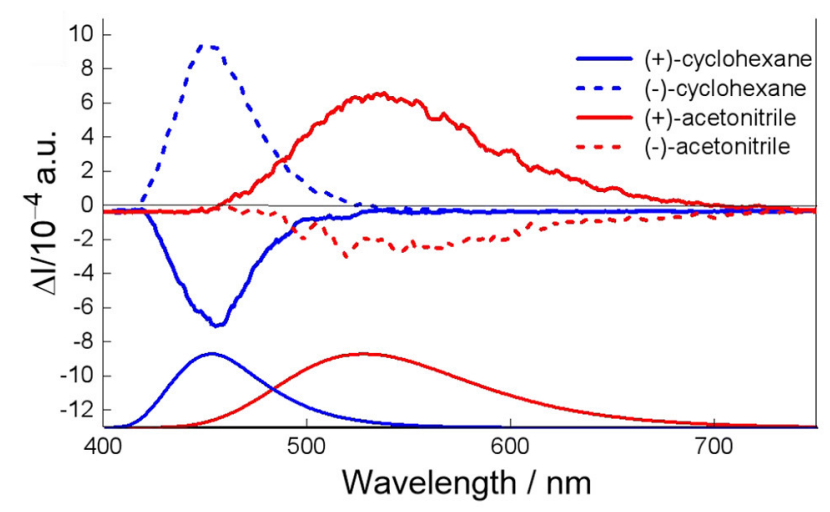

C

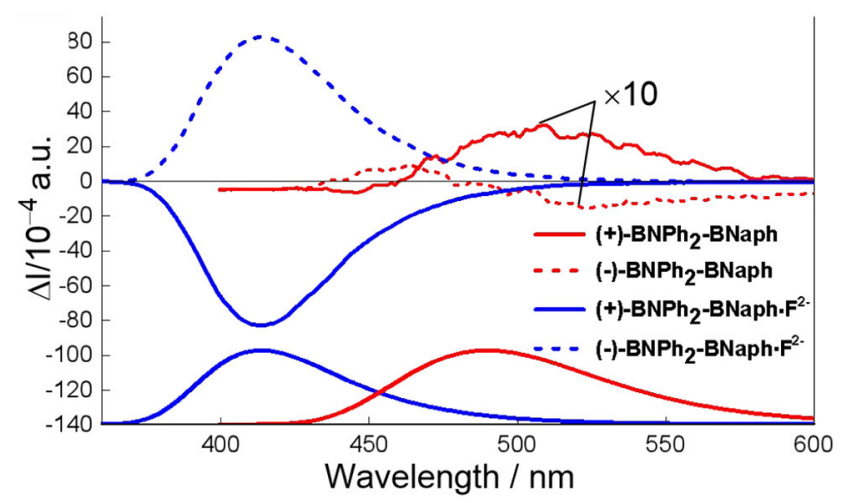

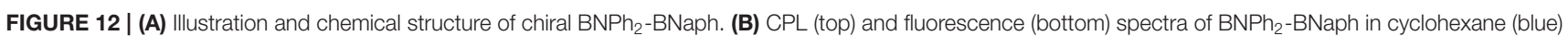
and $\mathrm{MeCN}$ (red), condition: $1.23 \times 10^{-4} \mathrm{M}, \lambda_{\mathrm{ex}}=340 \mathrm{~nm}$. (C) $\mathrm{CPL}$ (top) and fluorescence (bottom) changes of $\mathrm{BNPh}_{2}$-BNaph upon addition of $\mathrm{F}^{-}$ (tetrabutylammonium fluoride, 20 equiv). The measurements were carried out in THF solution $\left(\sim 1.23 \times 10^{-4} \mathrm{M}\right)$, under the excitation of $320 \mathrm{~nm}$. Reproduced with permission (Sun Z. et al., 2019). Copyright 2019, John Wiley and Sons.

Initial titration experiments were carried out on a solution of PTD-Z $\left(10 \mu \mathrm{M}\right.$, mixed $\left.\mathrm{CH}_{3} \mathrm{CN} / \mathrm{CHCl}_{3}\right)$. Addition of $\mathrm{ClO}^{-}$from $0-80 \mu \mathrm{M}$ was accompanied with emerging absorption at $375 \mathrm{~nm}$ and blue-shifted emission from 625 to $498 \mathrm{~nm}$. Further addition of $\mathrm{ClO}^{-}$to 10 equivalents of PTZ-D resulted in the formation of a sulfone. Structurally, the original left-handed helicoid structure of the PTZ-D gel changed to a right-handed structure. As a result, the original negative $C D$ signal at $438 \mathrm{~nm}$ gradually shifted to a positive signal at $460 \mathrm{~nm}$. Correspondently, the negative CPL signal initially decreased, and then reversed to positive. The change was ascribed to the different dihedral angles related to the phenothiazine unit before and after oxidation. In Feng's work, co-assembled supramolecular gels composed of C2-symmetric hydrogelators (LPF and DPF) and achiral naphthylamine isomers showed inversed supramolecular chirality and CD/CPL signals when the amine groups of the isomers shifted from the $\alpha$ - position to the $\beta$ - position (Yang et al., 2019). Along with the sign inversion, the CPL signals exhibited high |glum| values in the range of $5.62 \times 10^{-3}-8.74 \times 10^{-3}$. Furthermore, the inversion was studied from the intermolecular hydrogen bonds and $\pi-\pi$ stacking between the chiral and non-chiral components, which served as a rare example of achiral isomers used to form switchable CPL-active materials.

\section{CONCLUSIONS AND PERSPECTIVES}

Various CPL organic materials have been developed through tailoring either the molecular structures or their assembly behavior. Those with switchable CPL properties have been reviewed here, which possess considerable potential for applications in information processing and as intelligent sensors. The switchable behaviors have been classified based on different stimuli, including photo-irradiation, hostguest interaction, metal ions, $\mathrm{pH}$, solvent, temperature, etc. Photoactive CPL switches have been developed mainly from photochemical active units, such as covalently linked photochromic diaryethene/spiropyran and chiral units or by chiral assembly of photo-isomerizable cyanostilenes. Recently, a novel strategy based on photophysical excitation of selected excited states has been applied to achieve convertible CPL and CP-OURTP. For host-guest interaction-based switches, cryptand molecules with tunable size and adjustable binding affinity have been used to control both the formation of chiral inclusion pairs and to modulate the chirality transfer process in-between the components. Recent progress has come from a robust on-off CPL shuttle based on a single molecular machine. Metal ions serve as a versatile methodology with which to 


\section{A a}

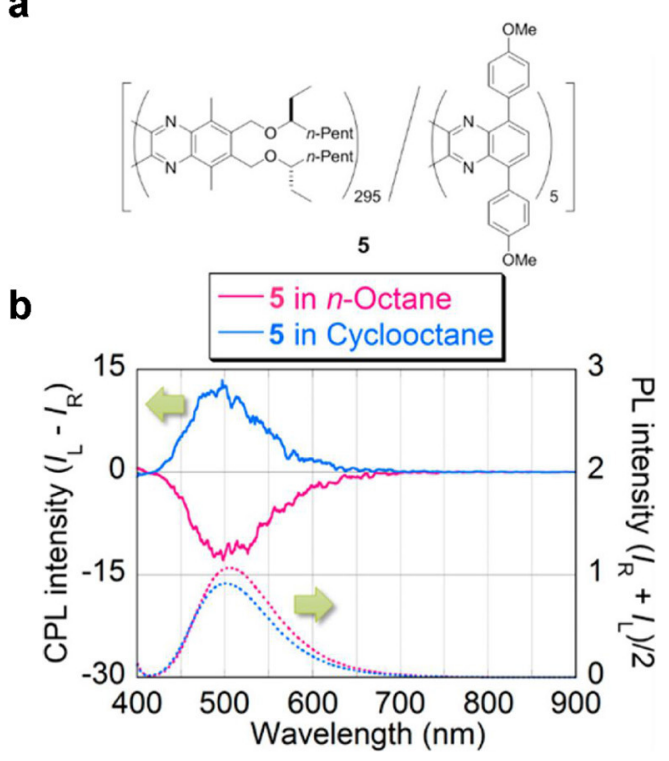

B a

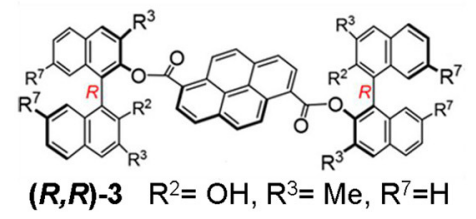

b

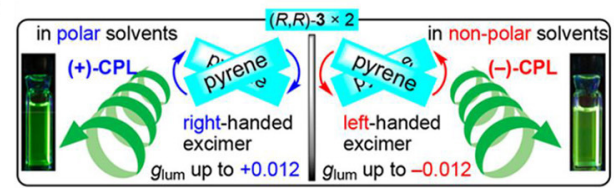

C

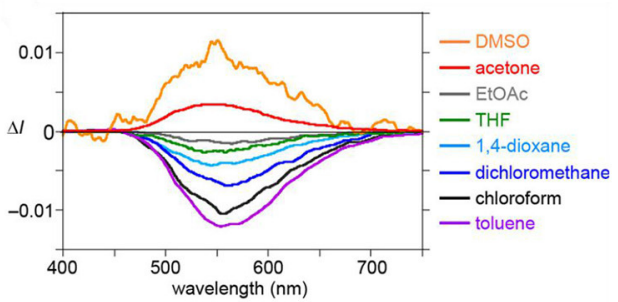

FIGURE 13 | (A) (a) Chemical sketch of polymer 5, and (b) CPL (upper) and PL (lower) spectra of $\mathbf{5}$ in n-octane (red) and cyclo-octane (blue) (2.70 × 10-2 $\mathrm{g} / \mathrm{L}$ ). (B) (a, b) Chemical structures and CPL illustration of $(R, R)-\mathbf{3}$; (c) CPL spectra of $(\boldsymbol{R}, \boldsymbol{R}) \mathbf{- 3}$ in different solvents. The solutions $\left(\sim 4.0 \times 10^{-3} \mathrm{M}\right)$ were excited at $355 \mathrm{~nm}$. (A) Reproduced with permission (Nishikawa et al., 2017). Copyright 2017, American Chemical Society. (B) Reproduced with permission (Takaishi et al., 2020). Copyright 2020, American Chemical Society.
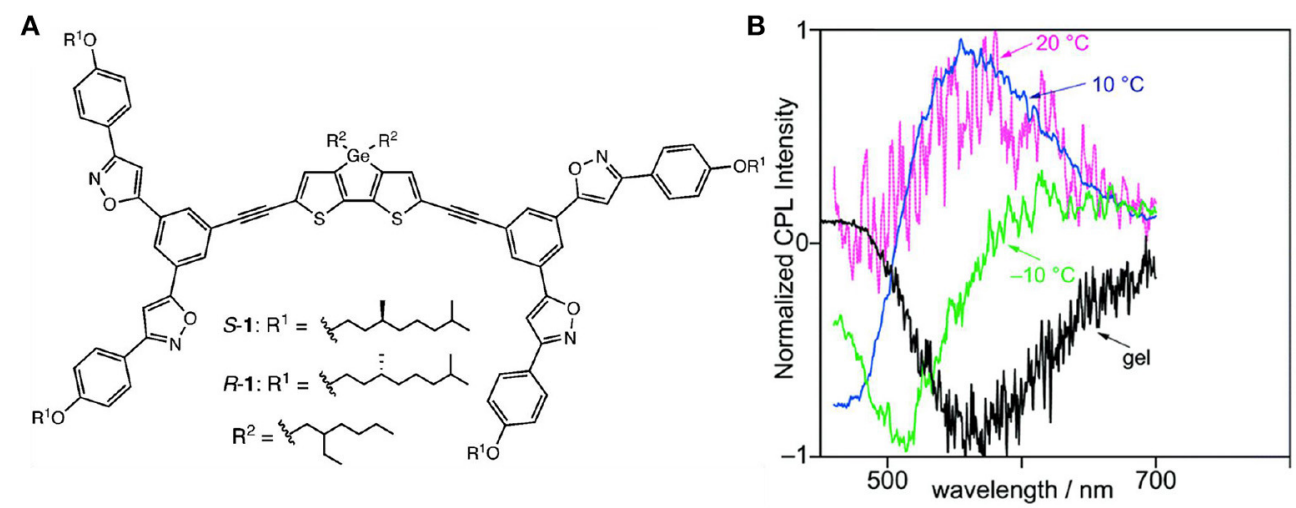

FIGURE 14 | (A) Skeleton of DTG possessing phenylisoxazoles and substituents. (B) CPL plots of S-1 from the methylcyclohexane solution ( 4.9 $\times 10^{-4}$ M) to gel, under the excitation of $420 \mathrm{~nm}$. Reproduced with permission (Hirano et al., 2019). Copyright 2019, Royal Society of Chemistry.

switch the CPL behaviors by forming highly directional and rigid complexes, which can dictate related electronic band structures, molecular conformations and helical orientations. Thus, multiple metal ions have been applied to reach CPL switches in emission color, intensity, and handedness. A majority of acid-base active CPL switches tune the emission wavelength by protonation/deprotonation process, and a recent on-off switch works by governing the protonation induced electron transfer. Solvent and temperature based CPL switches make impacts by the facile operation. The switch processes work usually by controlling the assembly process, through tuning the solvent-solute interaction forces by tuning the polarity of the solvents, or by controlled cooling. Besides those widely applied stimuli, other methods not mentioned here make use of anions (Maeda et al., 2011; Zhao Z. H. et al., 2019), energy transfer (Feng et al., 2018; Sun M. J. et al., 2019), and stoichiometry (Li et al., 2019).

To sum up, various types of stimuli for CPL switches work by either tuning molecular/electronic structures to change the related dynamic assembly behaviors or 
<smiles>CCCC[C@H](C)NC(=O)c1ccc(C2=CC(c3ccc(OC)cc3)=[O+][B-](F)(F)O2)cc1</smiles>

B a

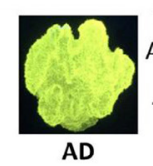
Thermal
Annealing
$\underset{170^{\circ} \mathrm{C}}{\longrightarrow}$
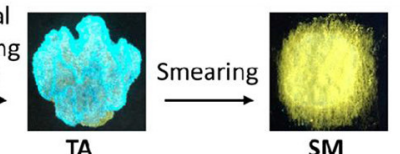

b
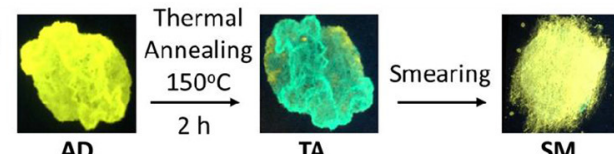

C
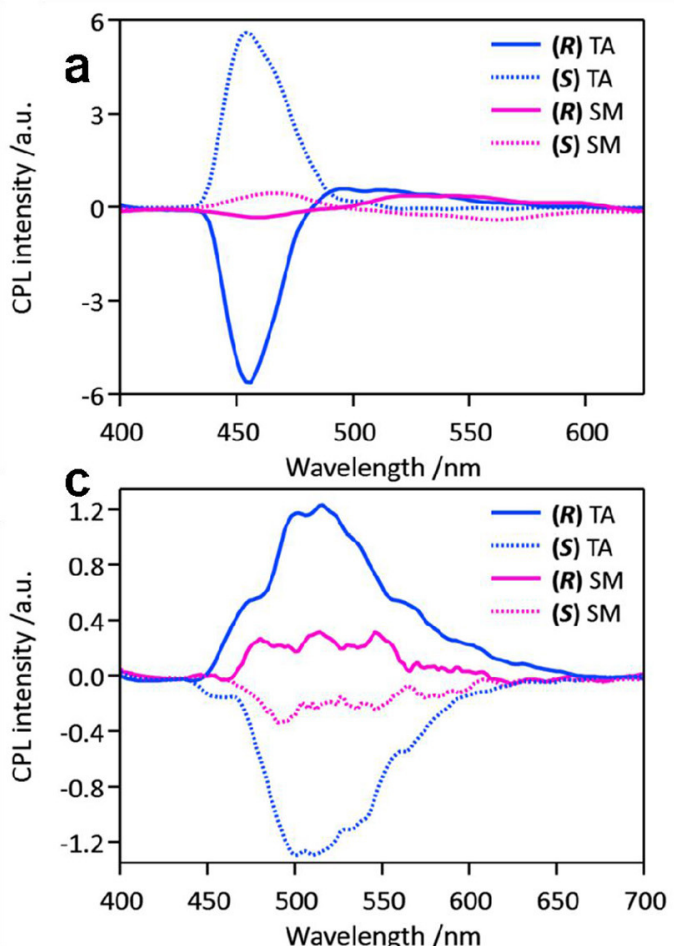
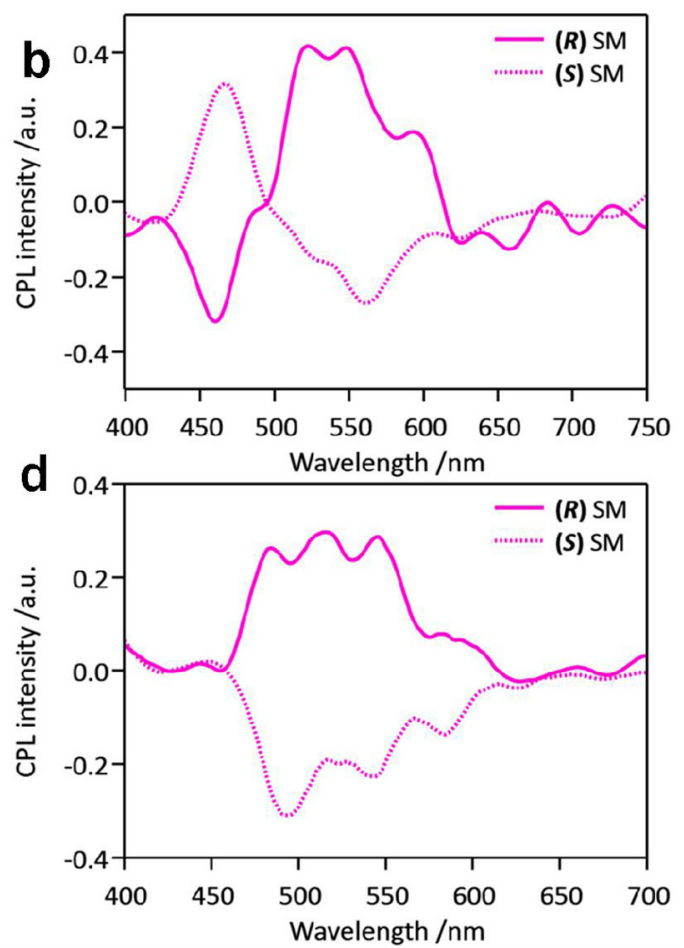

FIGURE 15 | (A) Chemical structures of (S)-DFB-Hex-amide and (S)-DFB-PhEt-amide. (B) Photographs of the samples obtained from deposition (AD), annealing (TA) and smearing (SM) for (S)-DFB-Hex-amide (a) and (S)-DFB-PhEt-amide (b). Under the excitation of $365 \mathrm{~nm}$. (C) CPL spectra of (R/S)-DFB-Hex-amide (a and b) and (R/S)-DFB-PhEt-amide(c and d). Solid-state samples were deposited on paper. Blue color indicates the thermally annealed (TA) samples, while the pink color represents the mechanically smeared samples. $(\mathrm{R})$ and $(\mathrm{S})$ isomers are plotted using solid and dashed lines, respectively. Reproduced with permission (Louis et al., 2019). Copyright 2019, Royal Society of Chemistry.

tuning external interactions in-between chiral and achiral components/moieties. Meanwhile, the many switch modes can be classified into two general fashions, simple on or off CPL switches or switching between/among multiple emissive CPL states. Up till now, the former have been in the majority. Meanwhile, a large part of the CPL switches rely on the synchronous luminescence switch. Thus, CPL switches capable of switching among multiple emissive states and CPL switches independent on the luminescence switch are still less explored and under demand. Hopefully, the methodologies discussed in the review will help to promote further research. 


\section{AUTHOR CONTRIBUTIONS}

YG and TH initiated the project. YG, CR, XL, and TH searched the data and wrote, revised, and completed the manuscript. All authors contributed to the article and approved the submitted version.

\section{FUNDING}

This work was supported by the Natural Science Foundation of Guangdong Province (2019A1515012094 and 2018A030310635),

\section{REFERENCES}

Chen, J., Chen, Y., Zhao, L., Feng, L., Xing, F., Zhao, C., et al. (2019). G-quadruplex DNA regulates invertible circularly polarized luminescence. J. Mater. Chem. C 7, 13947-13952. doi: 10.1039/c9tc04508b

David, A. H. G., Casares, R., Cuerva, J. M., Campana, A. G., and Blanco, V. (2019). A [2] rotaxane-based circularly polarized luminescence switch. J. Am. Chem. Soc. 141, 18064-18074. doi: 10.1021/jacs.9b07143

Fan, H., Jiang, H., Zhu, X., Guo, Z., Zhang, L., and Liu, M. (2019). Switchable circularly polarized luminescence from a photoacid co-assembled organic nanotube. Nanoscale 11, 10504-10510. doi: 10.1039/c9nr01959f

Feng, H.-T., Gu, X., Lam, J. W. Y., Zheng, Y.-S., and Tang, B. Z. (2018). Design of multi-functional AIEgens: tunable emission, circularly polarized luminescence and self-assembly by dark through-bond energy transfer. J. Mater. Chem. C 6, 8934-8940. doi: 10.1039/c8tc02504e

Gong, J., Yu, M., Wang, C., Tan, J., Wang, S., Zhao, S., et al. (2019). Reaction-based chiroptical sensing of $\mathrm{ClO}(-)$ using circularly polarized luminescence via self-assembly organogel. Chem. Commun. 55, 10768-10771. doi: $10.1039 / \mathrm{c} 9 \mathrm{cc} 05245 \mathrm{c}$

Guo, Y., Han, Y., and Chen, C. F. (2019). Construction of chiral nanoassemblies based on host-guest complexes and their responsive CD and CPL properties: chirality transfer from 2,6-helic[6]arenes to a stilbazolium derivative. Front. Chem. 7:543. doi: $10.3389 /$ fchem.2019.00543

Han, D., Han, J., Huo, S., Qu, Z., Jiao, T., Liu, M., et al. (2018). Proton triggered circularly polarized luminescence in orthogonal- and co-assemblies of chiral gelators with achiral perylene bisimide. Chem. Commun. 54, 5630-5633. doi: $10.1039 / \mathrm{c} 8 \mathrm{cc} 02777 \mathrm{c}$

Han, J., Guo, S., Lu, H., Liu, S., Zhao, Q., and Huang, W. (2018). Recent progress on circularly polarized luminescent materials for organic optoelectronic devices. Adv. Opt. Mater. 2010:1800538. doi: 10.1002/adom.201800538

Hashimoto, Y., Nakashima, T., Shimizu, D., and Kawai, T. (2016). Photoswitching of an intramolecular chiral stack in a helical tetrathiazole. Chem. Commun. 52, 5171-5174. doi: 10.1039/c6cc01277a

Hirano, K., Ikeda, T., Fujii, N., Hirao, T., Nakamura, M., Adachi, Y., et al. (2019). Helical assembly of a dithienogermole exhibiting switchable circularly polarized luminescence. Chem. Commun. 55, 10607-10610. doi: $10.1039 / \mathrm{c} 9 \mathrm{cc} 05253 \mathrm{~d}$

Homberg, A., Brun, E., Zinna, F., Pascal, S., Gorecki, M., Monnier, L., et al. (2018). Combined reversible switching of ECD and quenching of CPL with chiral fluorescent macrocycles. Chem. Sci. 9, 7043-7052. doi: 10.1039/c8sc02935k

Imai, Y., and Yuasa, J. (2019). Off-off-on chiroptical property switching of a pyrene luminophore by stepwise helicate formation. Chem. Commun. 55, 4095-4098. doi: $10.1039 / \mathrm{c} 9 \mathrm{cc} 01138 \mathrm{~b}$

Isla, H., Srebro-Hooper, M., Jean, M., Vanthuyne, N., Roisnel, T., Lunkley, J. L., et al. (2016). Conformational changes and chiroptical switching of enantiopure bis-helicenic terpyridine upon $\mathrm{Zn}(2+)$ binding. Chem. Commun. 52, 5932-5935. doi: 10.1039/c6cc01748g

Ito, H., Sakai, H., Okayasu, Y., Yuasa, J., Mori, T., and Hasobe, T. (2018). Significant Enhancement of absorption and luminescence dissymmetry factors in the far-red region: a Zinc(ii) homoleptic helicate formed by a pair of achiral dipyrromethene ligands. Chemistry 24, 16889-16894. doi: $10.1002 /$ chem.201804171
Shenzhen Basic Research Project of Science and Technology (JCYJ20170818142921044), and Natural Science Foundation of SZU (2018026).

\section{ACKNOWLEDGMENTS}

The authors wish to thank Prof. Andrew Grimsdale from Nanyang Technology University, Singapore, for the great comments on the manuscript.
Ji, L., He, Q., Niu, D., Tan, J., Ouyang, G., and Liu, M. (2019). Hostguest interaction enabled chiroptical photo-switching and enhanced circularly polarized luminescence. Chem. Commun. 55, 11747-11750. doi: 10.1039/c9cc06305f

Jin, Q., Chen, S., Jiang, H., Wang, Y., Zhang, L., and Liu, M. (2018). Self-assembly of amphiphilic schiff base and selectively turn on circularly polarized luminescence by $\mathrm{Al}(3)$. Langmuir 34, 14402-14409. doi: 10.1021/acs.langmuir.8b03019

Jin, X., Yang, D., Jiang, Y., Duan, P., and Liu, M. (2018). Light-triggered self-assembly of a cyanostilbene-conjugated glutamide from nanobelts to nanotoroids and inversion of circularly polarized luminescence. Chem. Commun. 54, 4513-4516. doi: 10.1039/C8CC00893K

Jintoku, H., Kao, M.-T., Guerzo, A. D., Yoshigashima, Y., Masunaga, T., Takafujiac, M., et al. (2015). Tunable Stokes shift and circularly polarized luminescence by supramolecular gel. J. Mater. Chem. C 3, 5970-5975. doi: 10.1039/C5TC0 $0878 \mathrm{~F}$

Li, H., Li, H., Wang, W., Tao, Y., Wang, S., Yang, Q., et al. (2020). Stimuli-responsive circularly polarized organic ultralong room temperature phosphorescence. Angew. Chem. Int. Ed. 59, 4756-4762. doi: 10.1002/anie.201915164

Li, P., Lu, B., Han, D., Duan, P., Liu, M., and Yin, M. (2019). Stoichiometrycontrolled inversion of circularly polarized luminescence in co-assembly of chiral gelators with an achiral tetraphenylethylene derivative. Chem. Commun. 55, 2194-2197. doi: 10.1039/c8cc08924h

Louis, M., Sethy, R., Kumar, J., Katao, S., Guillot, R., Nakashima, T., et al. (2019). Mechano-responsive circularly polarized luminescence of organic solid-state chiral emitters. Chem. Sci. 10, 843-847. doi: 10.1039/c8sc04026e

Ma, J. L., Peng, Q., and Zhao, C. H. (2019). Circularly polarized luminescence switching in small organic molecules. Chemistry 25, 15441-15454. doi: $10.1002 /$ chem. 201903252

Ma, K., Chen, W., Jiao, T., Jin, X., Sang, Y., Yang, D., et al. (2019). Boosting the circularly polarized luminescence of small organic molecules via multi-dimensional morphology control. Chem. Sci. 10, 6821-6827. doi: $10.1039 / \mathrm{c} 9 \mathrm{sc} 01577 \mathrm{a}$

Maeda, H., Bando, Y., Shimomura, K., Yamada, I., Naito, M., Nobusawa, K., et al. (2011). Chemical-stimuli-controllable circularly polarized luminescence from anion-responsive pi-conjugated molecules. J. Am. Chem. Soc. 133, 9266-9269. doi: $10.1021 / \mathrm{ja} 203206 \mathrm{~g}$

Meng, F., Li, F., Yang, L., Wang, Y., Quan, Y., and Cheng, Y. (2018). The amplified circularly polarized luminescence emission response of chiral 1,10 -binaphtholbased polymers via $\mathrm{Zn}(\mathrm{II})$-coordination fluorescence enhancement. J. Polym. Sci. Pol. Chem. 29, 1282-1288. doi: 10.1002/pola.29009

Miao, W., Wang, S., and Liu, M. (2017). Reversible quadruple switching with optical, chiroptical, helicity, and macropattern in self-assembled spiropyran gels. Adv. Funct. Mater. 27:1368. doi: 10.1002/adfm.201701368

Morcillo, S. P., Miguel, D., Alvarez de Cienfuegos, L., Justicia, J., Abbate, S., Castiglioni, E., et al. (2016). Stapled helical o-OPE foldamers as new circularly polarized luminescence emitters based on carbophilic interactions with $\mathrm{Ag}(\mathrm{i})$-sensitivity. Chem. Sci. 7, 5663-5670. doi: 10.1039/c6sc0 $1808 \mathrm{~d}$

Nishikawa, T., Nagata, Y., and Suginome, M. (2017). Poly(quinoxaline-2,3-diyl) as a multifunctional chiral scaffold for circularly polarized luminescent materials: 
color tuning, energy transfer, and switching of the CPL handedness. ACS Macro. Lett. 6, 431-435. doi: 10.1021/acsmacrolett.7b00131

Niu, D., Jiang, Y., Ji, L., Ouyang, G., and Liu, M. (2019). Self-assembly through coordination and pi-stacking: controlled switching of circularly polarized luminescence. Angew. Chem. Int. Ed. Engl. 58, 5946-5950. doi: 10.1002/anie.201900607

Ouyang, G., and Liu, M. (2020). Self-assembly of chiral supra-amphiphiles. Mater. Chem. Front (4), 155-167. doi: 10.1039/C9QM00571D

Pascal, S., Besnard, C., Zinna, F., Di Bari, L., Le Guennic, B., Jacquemin, D., et al. (2016). Zwitterionic [4] helicene: a water-soluble and reversible $\mathrm{pH}$-triggered ECD/CPL chiroptical switch in the UV and red spectral regions. Org. Biomol. Chem. 14, 4590-4594. doi: 10.1039/c6ob00752j

Pop, F., Zigon, N., and Avarvari, N. (2019). Main-Group-Based Electroand Photoactive Chiral Materials. Chem. Rev. 119, 8435-8478. doi: 10.1021/acs.chemrev.8b00770

Reine, P., Justicia, J., Morcillo, S. P., Abbate, S., Vaz, B., Ribagorda, M., et al. (2018). Pyrene-Containing ortho-Oligo(phenylene)ethynylene foldamer as a ratiometric probe based on circularly polarized luminescence. J. Org. Chem. 83, 4455-4463. doi: 10.1021/acs.joc.8b00162

Reiné, P., Ortuño, A. M., Resa, S., Álvarez de Cienfuegos, L., Blanco, V., Ruedas-Rama, M. J., et al. (2018). OFF/ON switching of circularly polarized luminescence by oxophilic interaction of homochiral sulfoxidecontaining o-OPEs with metal cations. Chem. Commun. 54, 13985-13988. doi: $10.1039 / \mathrm{c} 8 \mathrm{cc} 08395 \mathrm{a}$

Sakai, H., Kubota, T., Yuasa, J., Araki, Y., Sakanoue, T., Takenobu, T., et al. (2016). Protonation-induced red-coloured circularly polarized luminescence of [5]carbohelicene fused by benzimidazole. Org. Biomol. Chem. 14, 6738-6743. doi: $10.1039 / \mathrm{c} 60 \mathrm{~b} 00937 \mathrm{a}$

Saleh, N., Moore, B. 2nd, Srebro, M., Vanthuyne, N., Toupet, L., Williams, J. A., et al. (2015). Acid/base-triggered switching of circularly polarized luminescence and electronic circular dichroism in organic and organometallic helicenes. Chemistry 21, 1673-1681. doi: 10.1002/chem.201405176

Sang, Y., Han, J., Zhao, T., Duan, P., and Liu, M. (2019). Circularly polarized luminescence in nanoassemblies: generation, amplification, and application. Adv. Mater. e1900110. doi: 10.1002/adma.201900110

Sheng, Y., Ma, J., Liu, S., Wang, Y., Zhu, C., and Cheng, Y. (2016). Strong and reversible circularly polarized luminescence emission of a chiral 1,8-naphthalimide fluorophore induced by excimer emission and orderly aggregation. Chemistry 22, 9519-9522. doi: 10.1002/chem.201600891
Sun, M. J., Liu, Y., Zeng, W., Zhao, Y. S., Zhong, Y. W., and Yao, J. (2019). Photoluminescent anisotropy amplification in polymorphic organic nanocrystals by light-harvesting energy transfer. J. Am. Chem. Soc. 141, 6157-6161. doi: 10.1021/jacs.9b02055

Sun, Z. B., Liu, J. K., Yuan, D. F., Zhao, Z. H., Zhu, X. Z., Liu, D. H., et al. (2019). 2,2'-Diamino-6,6'-diboryl-1,1'-binaphthyl: a versatile building block for temperature-dependent dual fluorescence and switchable circularly polarized luminescence. Angew. Chem. Int. Ed. 58, 4840-4846. doi: 10.1002/anie.201813320

Takaishi, K., Iwachido, K., and Ema, T. (2020). Solvent-induced sign inversion of circularly polarized luminescence: control of excimer chirality by hydrogen bonding. J. Am. Chem. Soc. 142, 1774-1779. doi: 10.1021/jacs. $9 \mathrm{~b} 13184$

Wang, F., Ji, W., Yang, P., and Feng, C. L. (2019). Inversion of circularly polarized luminescence of nanofibrous hydrogels through co-assembly with achiral coumarin derivatives. ACS Nano 13, 7281-7290. doi: 10.1021/acsnano.9b03255

Yang, L., Wang, F., Auphedeous, D. Y., and Feng, C. (2019). Achiral isomers controlled circularly polarized luminescence in supramolecular hydrogels. Nanoscale 11, 14210-14215. doi: 10.1039/c9nr05033g

Zhang, D. W., Li, M., and Chen, C. F. (2020). Recent advances in circularly polarized electroluminescence based on organic light-emitting diodes. Chem. Soc. Rev. 49, 1331-1343. doi: 10.1039/c9cs00680j

Zhao, W. L., Li, M., Lu, H. Y., and Chen, C. F. (2019). Advances in helicene derivatives with circularly polarized luminescence. Chem. Commun. 55, 13793-13803. doi: 10.1039/c9cc06861a

Zhao, Z. H., Liang, X., He, M. X., Zhang, M. Y., and Zhao, C. H. (2019). Triarylborane-based [5]Helicenes with full-color circularly polarized luminescence. Org. Lett. 21, 9569-9573. doi: 10.1021/acs.orglett.9b03734

Conflict of Interest: The authors declare that the research was conducted in the absence of any commercial or financial relationships that could be construed as a potential conflict of interest.

Copyright $(2020$ Gao, Ren, Lin and He. This is an open-access article distributed under the terms of the Creative Commons Attribution License (CC BY). The use, distribution or reproduction in other forums is permitted, provided the original author(s) and the copyright owner(s) are credited and that the original publication in this journal is cited, in accordance with accepted academic practice. No use, distribution or reproduction is permitted which does not comply with these terms. 